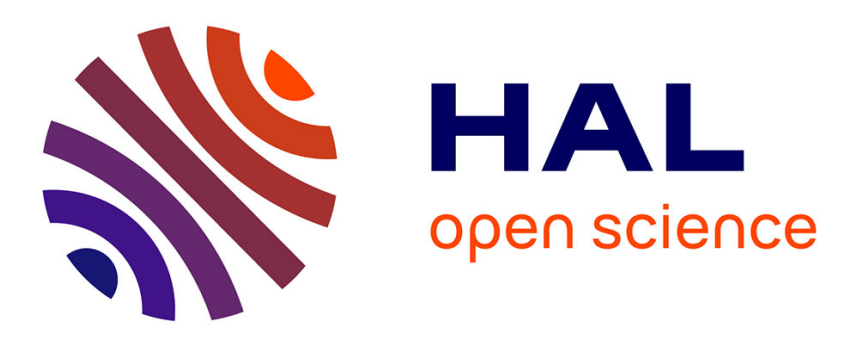

\title{
DFT studies of the bonding mechanism of 8-hydroxyquinoline and derivatives on the (111) aluminum surface
}

Fatah Chiter, Corinne Lacaze-Dufaure, Hao Tang, Nadine Pébère

\section{- To cite this version:}

Fatah Chiter, Corinne Lacaze-Dufaure, Hao Tang, Nadine Pébère. DFT studies of the bonding mechanism of 8-hydroxyquinoline and derivatives on the (111) aluminum surface. Physical Chemistry Chemical Physics, 2015, 17 (34), pp.22243-22258. 10.1039/c5cp03095a . hal-01264340

\author{
HAL Id: hal-01264340 \\ https://hal.science/hal-01264340
}

Submitted on 29 Jan 2016

HAL is a multi-disciplinary open access archive for the deposit and dissemination of scientific research documents, whether they are published or not. The documents may come from teaching and research institutions in France or abroad, or from public or private research centers.
L'archive ouverte pluridisciplinaire HAL, est destinée au dépôt et à la diffusion de documents scientifiques de niveau recherche, publiés ou non, émanant des établissements d'enseignement et de recherche français ou étrangers, des laboratoires publics ou privés. 


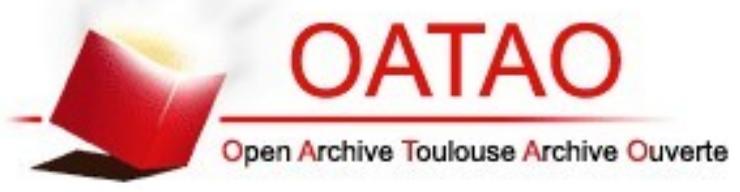

\section{Open Archive TOULOUSE Archive Ouverte (OATAO)}

OATAO is an open access repository that collects the work of Toulouse researchers and makes it freely available over the web where possible.

This is an author-deposited version published in : http://oatao.univ-toulouse.fr/ Eprints ID : 14581

To link to this article : DOI:10.1039/c5cp03095a

URL : http://dx.doi.org/10.1039/c5cp03095a

To cite this version : Chiter, Fatah and Lacaze-Dufaure, Corinne and Tang, Hao and Pébère, Nadine DFT studies of the bonding mechanism of 8-hydroxyquinoline and derivatives on the (111) aluminum surface. (2015) Physical Chemistry Chemical Physics (n³4). pp.22243-22258. ISSN 1463-9076

Any correspondance concerning this service should be sent to the repository administrator: staff-oatao@listes-diff.inp-toulouse.fr 


\title{
DFT studies of the bonding mechanism of 8-hydroxyquinoline and derivatives on the (111) aluminum surface
}

\author{
Fatah Chiter, ${ }^{a b}$ Corinne Lacaze-Dufaure, ${ }^{* a}$ Hao Tang ${ }^{b}$ and Nadine Pébère ${ }^{a}$ \\ The 8-hydroxyquinoline (8-HQ) molecule is an efficient corrosion inhibitor for aluminum and is also \\ used in organic electronic devices. In this paper, the adsorption modes of $8-\mathrm{HQ}$ and its derivatives \\ (tautomer, dehydrogenated and hydrogenated species) on the $\mathrm{Al}(111)$ surface are characterized using \\ dispersion corrected density functional theory calculations. The $8-\mathrm{HQ}$ molecule is physisorbed and is \\ chemisorbed on the aluminum surface with similar adsorption energy $(-0.86 \mathrm{eV}$ to $-1.11 \mathrm{eV})$ and these \\ adsorption modes are stabilized by vdW interactions. The binding of the dehydrogenated species is \\ the strongest one (adsorption energy of $-3.27 \mathrm{eV}$ to $-3.45 \mathrm{eV}$ ), followed by the tautomer molecule \\ $(-2.16 \mathrm{eV}$ to $-2.39 \mathrm{eV})$ and the hydrogenated molecule $(-1.71 \mathrm{eV})$ that bind weaker. In all the \\ chemisorbed configurations there is a strong electronic transfer from the Al substrate to the adsorbate \\ (0.72 e to $2.16 \mathrm{e})$. The adsorbate is strongly distorted and its deformation energy is high ( $0.55 \mathrm{eV}$ to $2.77 \mathrm{eV})$. \\ The analysis of the projected density of states onto the orbitals of the molecule and the electronic density \\ variation upon adsorption $(\Delta \rho)$ between the molecule and the surface account for covalent bonding.
}

\section{Introduction}

The 8-hydroxyquinoline (8-HQ) molecule is an organic species well-known for its affinity to interact with metals. The 8-HQ chelates metallic atoms ${ }^{1-4}$ and it was thus used in analytical chemistry to detect, separate and extract metallic ions by the formation of complexes. 8-HQ complexes were also good candidates for electronic, photoelectronic applications and emergency technologies ${ }^{5-7}$ based on organic light emitting diodes (OLEDs) because of nonlinear optical properties and strong fluorescence in solid state and aqueous solutions.

The 8-HQ molecule also interacts with metallic surfaces and was studied for the protection against corrosion of aluminum and its alloys. These materials are widely used in aerospace industries due to their high strength-to-weight ratio, outstanding mechanical properties and good resistance to corrosion. However, the protective aluminum oxide thin film can be destroyed in contact with aggressive elements such as chlorides ions or in acidic medium. ${ }^{8}$ Traditionally, chromate salts are used as efficient corrosion inhibitors. However due to the high toxicity and carcinogenic risks of these compounds, their $\mathrm{u}$ industrial applications is strongly restricted. As a consequ intense research efforts are being undertaken to find environment friendly substitutes and many experimental ' explore alternative ways to protect aluminum and its against corrosion. ${ }^{9-21}$ The 8-HQ molecule showed corr inhibition efficiency in several experimental works. ${ }^{10,22-\text { : }}$ instance, Pébère et l. $^{22}$ investigated the corrosion of aluminum in neutral and acidic chloride solutions. They cluded that in neutral solution, the presence of the slowed down the destruction of the aluminum oxide lay pitting, and suggested that 8-HQ prevented the adsorpti chloride ions. The same conclusion was reached in the $\mathrm{w}$ Lamaka et $a l .{ }^{10}$ In another study on 5083 aluminum al. acidic and alkaline solutions, Yaro et $a .^{23}$ showed that decreased the cathodic reduction and inhibited thus the sion. Finally, Song-mei et al. ${ }^{24}$ observed that the corr active sites on the surface of 2024 aluminum alloy were bl by the presence of 8-HQ and its derivatives in chloride sol 1

From a computational point of view, most studies o corrosion inhibiting molecules considered the propert: the molecule in the gas phase, without taking into accous substrate. The experimental inhibition efficiency was disc through electronic properties (molecular frontier orbitals, $\mathrm{Hc}$ LUMO gap) and molecular reactivity indicators (hardness ness, Fukui indices) of the free organic species. Complete $\mathrm{r}$ were published by Gece $e^{17,18}$ and Obot et al..$^{25}$ on this subject. 
description of the corrosion inhibition mechanism, which takes into account both the corrosion inhibition molecule and the metallic surface, is very complex and few studies attempted to address this challenge. ${ }^{26-36}$ The studies of Kokalj et al. ${ }^{28-33}$ on the adsorption of benzotriazole and derivatives on the $\mathrm{Cu}(111)$ surface were for instance particularly meaningful for the understanding of the corrosion inhibition process of organic molecules. In connection with the subject of our work, some calculations performed to understand the mechanism of the adsorption of molecules on the aluminum,,$^{20,29,30,37} \alpha$-alumina ${ }^{38-42}$ and boehmite ${ }^{34-36}$ surfaces were also particularly relevant. But none of them were related to the adsorption of the 8-HQ molecule on metallic surfaces with the goal to understand the binding mechanism. For this purpose, the understanding of the molecule/ substrate interface is of great importance because this is a complex system with properties that depends on the bonding. ${ }^{26,27,43}$ To our knowledge, only few investigations in relation with 8-HQ were carried out on the adsorption of the tris(8-hydroxyquinoline)aluminum $\left(\mathrm{Alq}_{3}\right)$ complex on cobalt, ${ }^{44}$ magnesium ${ }^{45}$ and aluminum ${ }^{46,47}$ surfaces. The unique DFT study of the interaction of the 8-HQ single molecule with a metallic surface was done on $\mathrm{Cu}(111)$ surface. The calculations were used to interpret intermolecular hydrogen bonding in small 8-HQ molecular assemblies on the $\mathrm{Cu}(111)$ surface observed experimentally by non-contact atomic force microscopy (NC-AFM) images. ${ }^{48}$

In this work, we focused on the adsorption of the 8-HQ molecule and its derivatives on the surface of aluminum. This adsorption on $\mathrm{Al}(111)$ was realistic, because it corresponds to experimental conditions in acidic and alkaline medium where the oxide layer is dissolved and in a neutral medium where the oxide layer could be defective with a direct interaction of the inhibitor and the bare metallic surface. In addition to the study of the 8-HQ molecule, we investigated the interaction of derivatives (tautomer, dehydrogenated and hydrogenated 8-HQ, which could be present in the experimental medium) with the $\mathrm{Al}(111)$ substrate. All calculations were performed by using dispersion corrected DFT. We first present here calculations on the free molecules. We conclude that the dehydrogenated 8-HQ is supposed to be the more reactive species and we expected an electronic transfer from the substrate to the molecule. This could be deduced from the comparison of the energy of the frontier orbitals for the four free species. In a second part, we present the results concerning the adsorption of the 8-HQ and derivatives on the $\mathrm{Al}(111)$ surface at low coverage. The 8-HQ was the only molecule that showed a physisorbed configuration ( $\varphi$ configuration) dominated by van der Waals interactions between the molecule and the surface. Chemisorbed configurations were found for the 8 -HQ molecule $\left(\chi 1\right.$ and $\chi^{2}$ configurations), its tautomer ( $\tau 1$ and $\tau 2$ configurations), its dehydrogenated species ( $\delta 1, \delta 2$ and $\delta 3$ configurations) and the hydrogenated species ( $\eta$ configuration). The strongest bonding to the aluminum surface was found for the dehydrogenated species, followed by the tautomer, the hydrogenated molecule and finally the native 8-HQ. For the four compounds, the chemisorption process was in relation with a strong electronic transfer from the substrate to the organic species and a strong geometrical deformation of the adsorbed molecule. On the contrary, only a small deformation of the metallic surface could be observed upon adsorption. A detailed analysis of the charge density change (before and after adsorption) and of the projected density of states onto the molecular orbitals demonstrated a strong covalent bonding. Nevertheless van der Waals interactions at the molecule/substrate interface were not negligible at all and accounted for stable adsorption configurations on the metallic surfaces.

\section{Computational details}

All calculations were performed in the framework of the density functional theory (DFT) using the Vienna Ab initio Simulation Package $^{49-51}$ (VASP) and the Projector Augmented Wave (PAW) method. ${ }^{52,53}$ We used the Generalized Gradient Approximation (GGA) of the exchange-correlation term and the Perdew-BurkeErnzehof $^{54}$ (PBE) functional. Convergence with respect to cutoff energy $\left(E_{\text {cut }}\right)$, Methfessel-Paxton ${ }^{55}$ smearing $\sigma$ and size of Monkhorst-Pack ${ }^{56}$ mesh of $k$-points was carefully checked in order to have the same energy precision in all calculations (less than $1 \mathrm{meV}$ per atom). If not otherwise stated, we used $E_{\text {cut }}=$ $450 \mathrm{eV}$, and $\sigma=0.1 \mathrm{eV}$. The grid of $k$-points was set to $(3 \times 3 \times 1)$ for slab calculations. Spin polarization was taken into account. Atomic positions were relaxed with conjugate gradient algorithm until forces on each moving atom were less than $0.02 \mathrm{eV}^{-1}$.

For molecule/surface calculations, we used an asymmetric slab and the molecule was adsorbed on one side of the slab (top layer). The Al substrate was described by a 4 atomic layers monoclinic $(5 \times 6)$ slab of 120 atoms. Atoms of the two bottom metallic layers were kept fixed at their position in bulk during all calculations. Only the atoms of the two top layers of the slab and of the molecule were allowed to relaxed. The large supercell $(14.28 \AA \times 17.14 \AA)$ was necessary to minimize the interaction between the molecule and its periodic images in the $(x \times y)$ directions. Moreover the vacuum region was set to about $18 \AA$, which corresponded to 8 atomic layers thick to minimize the interactions in the $z$ direction.

As it is well known that classical DFT does not include the dispersive van der Waals (vdW) interactions, different corrective methods were proposed in the literature. ${ }^{57-60}$ Even if these corrections improved significantly the description of molecules, molecular crystals and molecule/surface systems, the benefit of these contributions on metallic materials and surfaces could be questionable. The van der Waals interactions based on DFT-D2 ${ }^{58}$ as implemented in VASP was modified to consider the vdW interactions only at the aluminum/molecule interface $E_{\mathrm{slab} / \mathrm{mol}}^{\mathrm{vdW}}$. The total energy was therefore calculated by:

$$
E^{\mathrm{DFT}-\mathrm{D}}=E^{\mathrm{DFT}}+E_{\mathrm{slab} / \mathrm{mol}}^{\mathrm{vdW}}
$$

The adsorption energy was calculated as:

$$
E_{\text {ads }}=E_{\text {slab }+ \text { mol }}-E_{\text {slab/vac }}-E_{\text {mol } / v a c}
$$

where $E_{\text {slab+mol }}$ was the total energy of the system with the molecule adsorbed on the $\mathrm{Al}(111)$ surface. $E_{\text {slab/vac }}$ and $E_{\mathrm{mol} / \mathrm{vac}}$ were the energy of the clean relaxed $\mathrm{Al}(111)$ slab and of the free 
molecule optimized in vacuum that were calculated without dispersive corrections.

The molecule deformation energy was determined as:

$$
E_{\mathrm{mol}}^{\mathrm{deform}}=E_{\mathrm{mol} / \mathrm{ads}}-E_{\mathrm{mol} / \mathrm{vac}}
$$

where $E_{\mathrm{mol} / \mathrm{ads}}$ and $E_{\mathrm{mol} / \mathrm{vac}}$ were the total energy of the isolated molecule at the geometry after adsorption and of the free molecule optimized in vacuum, respectively.

The substrate deformation energy was also calculated as:

$$
E_{\text {slab }}^{\text {deform }}=E_{\text {slab/ads }}-E_{\text {slab/vac }}
$$

where $E_{\text {slab/ads }}$ and $E_{\text {slab/vac }}$ were the total energy of the isolated slab at the geometry after adsorption and the total energy of the slab relaxed, respectively.

Finally, we calculated the interaction energy as:

$$
E_{\text {int }}=E_{\text {ads }}-E_{\text {slab }}^{\text {deform }}-E_{\text {mol }}^{\text {deform }}
$$

where $E_{\text {ads }}$ was the adsorption energy, $E_{\mathrm{slab}}^{\text {deform }}$ and $E_{\mathrm{mol}}^{\text {deform }}$ were the slab and molecule deformation energies, respectively.

The net charge variation was determined on each atom by:

$$
\Delta Q_{x}=Q_{x}^{\mathrm{ads}}-Q_{x}^{\mathrm{vac}}
$$

where the $Q_{x}^{\text {ads }}$ and $Q_{x}^{\text {vac }}$ were the net charge on each atom $x$ (Bader population analysis ${ }^{61}$ ) of the molecule and the slab before and after adsorption, respectively.

We plotted the electronic density variation as:

$$
\Delta \rho=\rho_{\text {slab }+ \text { mol }}-\rho_{\text {slab } / \text { ads }}-\rho_{\text {mol } / \text { ads }}
$$

where $\rho_{\text {slab+mol }}$ was the electron distribution on the system, $\rho_{\text {slab/ads }}$ and $\rho_{\text {mol/ads }}$ were the electron distribution on the isolated substrate and molecule at the geometry after adsorption, respectively.

\section{Results and discussion}

\subsection{Free 8-HQ molecule and derivatives}

The 8-hydroxyquinoline (8-HQ) molecule is an organic compound (18 atoms) that crystallizes in the orthorhombic space group Fdd2. ${ }^{62}$ Depending on the nature of the solvent, the 8-HQ molecule can be present under the $\alpha$ form (with intramolecular hydrogen bonding), $\beta$ form (without intramolecular hydrogen bonding) and tautomeric form (see Fig. 1). This latter form is supposed to be present in polar solvents. ${ }^{63,64}$ The $\mathrm{p} K_{\mathrm{a}}$ values of 8-HQ in aqueous solutions at $20{ }^{\circ} \mathrm{C}$ are $5.13\left(\mathrm{NH}^{+} / \mathrm{N}\right)$ and 9.89 $\left(-\mathrm{OH} / \mathrm{O}^{-}\right)$. For $\mathrm{pH}$ around 7 , the predominant form is the $8-\mathrm{HQ}$ which coexists with the tautomeric form and we investigated the adsorption of these two species on the $\mathrm{Al}(111)$ surface. In highly basic solutions the 8-HQ molecule can be present in the dehydrogenated form and we also studied the adsorption on $\mathrm{Al}(111)$ of the dehydrogenated 8-HQ molecule that is a radical species. This was also motivated by the fact that the dehydrogenation of the 8-HQ on metals was reported in the literature, i.e. on $\mathrm{Cu}(111) .{ }^{48}$ We were also interested by the adsorption of the hydrogenated 8-HQ molecule, which could be present in acidic solution for $\mathrm{pH}<3.8 .^{65}$
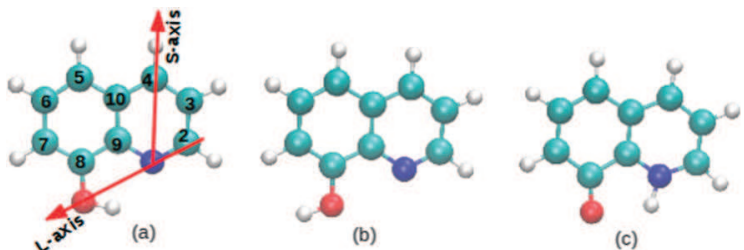

(c)
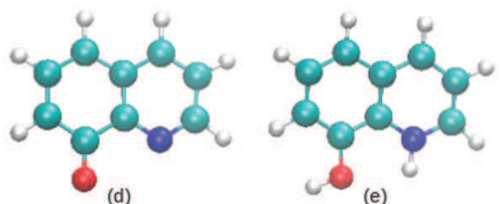

Fig. 1 (a) $\propto$ 8-HQ molecule with carbon numeration, long axis ( $L$-axis) and short (S-axis); (b) $\beta 8-\mathrm{HQ}$, (c) tautomer; (d) dehydrogenated 8-HQ; (e) hydrogenated $8-\mathrm{HQ}$; red, blue, cyan and white spheres correspond to the oxygen, nitrogen, carbon and hydrogen atoms respectively.

We first performed computations on the isolated 8-HQ molecule ( $\alpha$ and $\beta$ forms) and its tautomer. In these $0 \mathrm{~K}$ gas phase calculations, the $\alpha$ form was the most stable (with a total energy of $0.37 \mathrm{eV}$ lower than $\beta$, and $0.50 \mathrm{eV}$ lower than tautomer) due to the intramolecular H-bond. It was also previously shown in the literature by using the polarized continuum model that for the native $8-\mathrm{HQ}$, the $\alpha$ form was the more stable form in polar solvent ${ }^{64}$ and the rotational barrier for the $\mathrm{OH}$ group was calculated to be $0.11 \mathrm{eV}$ and $0.40 \mathrm{eV}$ for the $\beta \rightarrow \alpha$ and $\alpha \rightarrow \beta$ conformational changes respectively (B3LYP calculations). We thus assumed that the $\alpha$ isomer is promptly formed. We therefore only studied the interaction of the most stable form of the 8-HQ molecule ( $\alpha$ form), with the aluminum surface. The results of these latter computations are presented in the following section. The obtained geometrical information for the $\alpha$ 8-HQ free molecule (calculated in vacuum, bond lengths presented in Table 1, bending angles and torsional angles not detailed here) were in good agreement with experimental results, ${ }^{62}$ and other calculations ${ }^{63-65}$ presented in the literature. For the tautomer molecule, the calculated geometrical parameters showed a change in the bond lengths involving the $\mathrm{O}$ and $\mathrm{N}$ atoms in comparison to the bond lengths in the $\alpha 8-\mathrm{HQ}$.

We also considered the free dehydrogenated and hydrogenated 8-HQ species. The geometrical parameters of these species were only slightly different than that of the $\alpha$ 8-HQ molecule (see Table 1), except for chemical bonds close to the nitrogen and oxygen atoms. For the dehydrogenated 8-HQ the $\mathrm{C}_{7}-\mathrm{C}_{8}$ and $\mathrm{C}_{8}-\mathrm{C}_{9}$ bond lengths were increased of about $0.07 \AA$, and the $\mathrm{C}_{8}-\mathrm{O}$ bond length was shorten of $0.10 \AA$. These variations were qualitatively similar to that of the tautomer. In the hydrogenated 8-HQ molecule the $\mathrm{C}_{2}-\mathrm{N}$ bond length was increased of about $0.06 \AA$, and the $\mathrm{C}_{2}-\mathrm{C}_{3}$ bond length was decreased of $0.04 \AA$, (compared to the 8-HQ molecule).

Atomic charges (in Table 2) calculated with the Bader population analysis method, ${ }^{61}$ showed negative charges on oxygen and nitrogen atoms for the 8-HQ molecule and its derivatives. The charge variation on these atoms under different form was directly linked to the presence or not of the hydrogen atom on the $\mathrm{O}$ and $\mathrm{N}$ atoms. 
Table 1 Bond lengths (in $\AA$ ) of the $\alpha$ 8-HQ molecule, tautomer, dehydrogenated and hydrogenated 8-HQ, before and after adsorption on the Al(111) surface; the experimental values correspond to the crystallized $8-\mathrm{HQ}$ molecule ${ }^{62}$

\begin{tabular}{|c|c|c|c|c|c|c|c|c|c|c|c|c|c|c|}
\hline Exp. $^{62}$ & $\begin{array}{l}d_{\mathrm{C}_{2} \mathrm{C}_{3}} \\
1.428\end{array}$ & $\begin{array}{l}d_{\mathrm{C}_{3} \mathrm{C}_{4}} \\
1.443\end{array}$ & $\begin{array}{l}d_{\mathrm{C}_{4} \mathrm{C}_{10}} \\
1.423\end{array}$ & $\begin{array}{l}d_{\mathrm{C}_{10} \mathrm{C}_{5}} \\
1.443\end{array}$ & $\begin{array}{l}d_{\mathrm{C}_{5} \mathrm{C}_{6}} \\
1.357\end{array}$ & $\begin{array}{l}d_{\mathrm{C}_{6} \mathrm{C}_{7}} \\
1.431\end{array}$ & $\begin{array}{l}d_{\mathrm{C}_{7} \mathrm{C}_{8}} \\
1.412\end{array}$ & $\begin{array}{l}d_{\mathrm{C}_{8} \mathrm{C}_{9}} \\
1.411\end{array}$ & $\begin{array}{l}d_{\mathrm{C}_{9} \mathrm{C}_{10}} \\
1.449\end{array}$ & $\begin{array}{l}d_{\mathrm{C}_{9} \mathrm{~N}} \\
1.383\end{array}$ & $\begin{array}{l}d_{\mathrm{C}_{2} \mathrm{~N}} \\
1.350\end{array}$ & $\begin{array}{l}d_{\mathrm{C}_{8} \mathrm{O}} \\
1.390\end{array}$ & $d_{\mathrm{OH}}$ & $d_{\mathrm{NH}}$ \\
\hline \multicolumn{15}{|l|}{$\alpha 8-\mathrm{HQ}$} \\
\hline Isolated & 1.415 & 1.381 & 1.418 & 1.419 & 1.383 & 1.414 & 1.384 & 1.431 & 1.429 & 1.361 & 1.325 & 1.355 & 0.991 & 2.026 \\
\hline$\varphi$ & 1.414 & 1.387 & 1.420 & 1.421 & 1.389 & 1.414 & 1.389 & 1.432 & 1.429 & 1.360 & 1.331 & 1.354 & 0.995 & 2.015 \\
\hline$\chi 1$ & 1.435 & 1.378 & 1.449 & 1.405 & 1.400 & 2.397 & 1.398 & 1.408 & 1.424 & 1.397 & 1.455 & 1.402 & 0.992 & 2.242 \\
\hline$\chi^{2}$ & 1.365 & 1.471 & 1.475 & 1.406 & 1.401 & 1.401 & 1.395 & 1.404 & 1.413 & 1.413 & 1.416 & 1.390 & 0.995 & 2.111 \\
\hline \multicolumn{15}{|c|}{ Tautomer } \\
\hline Isolated & 1.404 & 1.388 & 1.421 & 1.406 & 1.400 & 1.401 & 1.425 & 1.464 & 1.432 & 1.349 & 1.337 & 1.272 & 2.034 & 1.043 \\
\hline$\tau 1$ & 1.453 & 1.362 & 1.453 & 1.406 & 1.397 & 1.395 & 1.413 & 1.412 & 1.409 & 1.449 & 1.511 & 1.351 & 2.466 & 1.027 \\
\hline$\tau 2$ & 1.353 & 1.470 & 1.478 & 1.406 & 1.399 & 1.399 & 1.409 & 1.409 & 1.404 & 1.442 & 1.438 & 1.350 & 2.324 & 1.027 \\
\hline \multicolumn{15}{|c|}{ Dehydrogenated 8-HQ } \\
\hline Isolated & 1.408 & 1.383 & 1.414 & 1.426 & 1.399 & 1.386 & 1.455 & 1.496 & 1.429 & 1.344 & 1.334 & 1.249 & - & - \\
\hline$\delta 1$ & 1.465 & 1.362 & 1.452 & 1.403 & 1.401 & 1.402 & 1.401 & 1.416 & 1.419 & 1.371 & 1.449 & 1.388 & - & - \\
\hline$\delta 2$ & 1.368 & 1.465 & 1.475 & 1.403 & 1.401 & 1.397 & 1.413 & 1.425 & 1.421 & 1.408 & 1.406 & 1.346 & - & - \\
\hline$\delta 3$ & 1.402 & 1.386 & 1.419 & 1.418 & 1.385 & 1.413 & 1.387 & 1.417 & 1.425 & 1.372 & 1.344 & 1.367 & - & - \\
\hline \multicolumn{15}{|c|}{ Hydrogenated 8-HQ } \\
\hline Isolated & 1.377 & 1.408 & 1.431 & 1.414 & 1.393 & 1.399 & 1.398 & 1.401 & 1.425 & 1.389 & 1.383 & 1.386 & 0.972 & 1.013 \\
\hline$\eta$ & 1.350 & 1.472 & 1.476 & 1.407 & 1.397 & 1.399 & 1.399 & 1.401 & 1.407 & 1.439 & 1.439 & 1.376 & 0.979 & 1.023 \\
\hline
\end{tabular}

Table 2 Net charges $Q_{x}$ (in e) on each atom $x$ of the isolated molecules (Bader analysis)

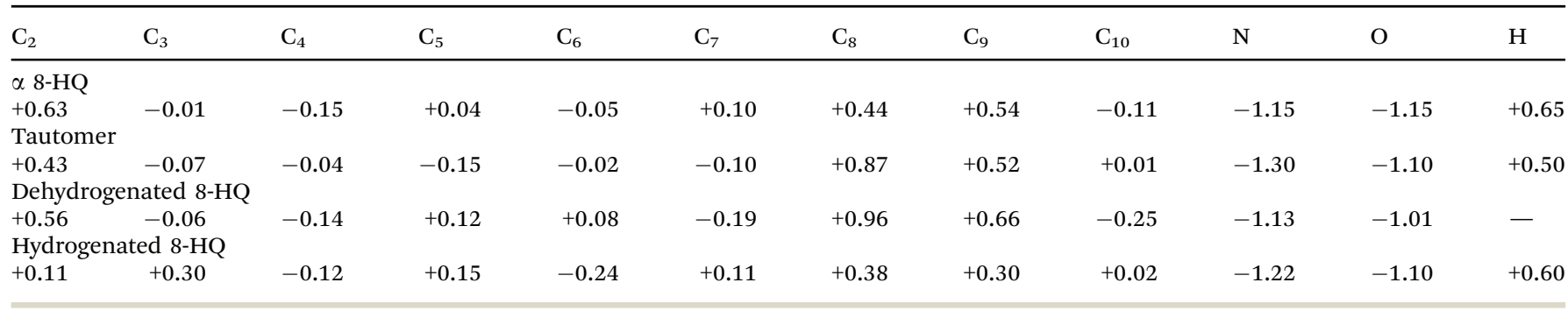

The adsorption of organic molecules could be roughly understood through the analysis of molecular frontier orbitals (the highest occupied molecular orbital (HOMO) and lowest unoccupied molecular orbital (LUMO)). As shown in Fig. 2, the HOMO of the tautomer was about $0.80 \mathrm{eV}$ higher than that of $\alpha$ 8-HQ, while the LUMO of the tautomer was about $0.60 \mathrm{eV}$ lower

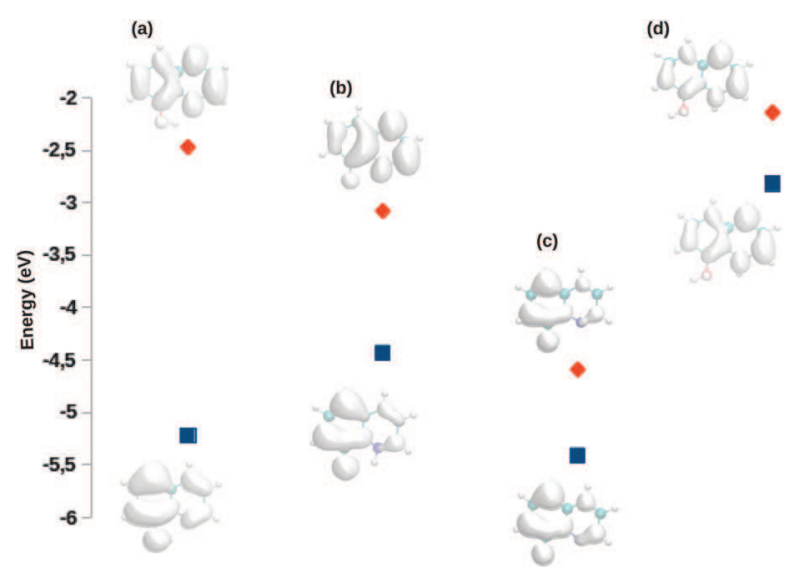

Fig. 2 Molecular orbitals of the 8-HQ molecule and derivatives. $\mathrm{HOMO}$ at bottom and LUMO at top. (a) $\alpha 8-\mathrm{HQ}$; (b) tautomer; (c) dehydrogenated 8-HQ; (d) hydrogenated 8-HQ. than the LUMO of the $\alpha 8$-HQ molecule. This was an indication that the tautomer was more reactive with more facility to give and to receive electrons than the $\alpha 8$-HQ molecule. The dehydrogenated and hydrogenated 8-HQ were radicals in their ground state. The LUMO had the same form as the HOMO as the orbital was singly occupied due to the lost or excess of one electron for the dehydrogenated or hydrogenated molecules respectively. The LUMO of the dehydrogenated 8-HQ species had the lowest energy among the three forms of the 8-HQ molecule and its derivatives investigated here and this suggested that the dehydrogenated 8-HQ could more easily gain electrons. The hydrogenated 8-HQ had the highest HOMO energy, suggesting this time that the hydrogenated 8-HQ could more easily give electrons than the other three species. The energy of its LUMO orbital was the highest one and hydrogenated 8-HQ might not gain easily electrons.

\subsection{Adsorption of 8-HQ and its derivatives on the $\mathrm{Al}(111)$ surface}

We studied the adsorption of 8-HQ and its tautomeric, dehydrogenated and hydrogenated forms on a 4-layers $\mathrm{Al}(111)$ slab. As mentioned previously, we limited ourselves to a low coverage case by using a supercell with large lateral size. In order to identify the most stable adsorption sites, we selected for each molecule 
different initial positions (with $\mathrm{O}$ and $\mathrm{N}$ on top, hep and fcc positions of the surface sites) and put initially the molecule parallel to the surface. Furthermore, in order to overcome a possible activation energy barrier between physisorption and chemisorption states, different initial molecule-surface distances were chosen.

3.2.1 Physisorption. At the end of the optimization process, a physisorption state was obtained only for the $\alpha 8$-HQ molecule with an initial molecule-surface distance larger than $2.31 \AA$, ( $\varphi$ configuration in Table 3 and in Fig. 3$)$. The calculated PBE-D adsorption energy was $-0.90 \mathrm{eV}$, without noticeable deformation for both the molecule and the substrate (see in Table 3 the deformation energy of $0.01 \mathrm{eV}$ ). For this configuration, the molecule was flat and parallel to the surface at a normal distance of about 3.20 A. We also investigated this state without taking into account the dispersion corrections. The optimized adsorption conformation of the molecule was then only slightly different but we calculated an adsorption energy of $-0.06 \mathrm{eV}$ (PBE) and an average molecule-surface distance of $3.80 \AA$. This confirmed that the $\varphi$ configuration was essentially stabilized by the van der Waals interactions between the molecule and the surface which is typical of a physisorbed state. As expected the bond lengths and the angles in the $\alpha$ 8-HQ molecule were not modified by the physisorption process (see in Table 1). In this case, Bader charge analysis showed a minor transfer of 0.20 electrons from the substrate to the molecule. We plotted the charge distribution variation $\Delta \rho$ and for this physisorbed configuration, the electronic density between the molecule and the slab was very low $\left(<-0.002\right.$ e $\AA^{-3}$, Fig. 4$)$. This physisorbed configuration had the long axis ( $L$-axis, through $\mathrm{O}, \mathrm{N}$ and $\mathrm{C}_{2}$ atoms, see Fig. 1) of 8-HQ oriented along the [212̄] direction with the oxygen atom located on top of a surface aluminum atom, while the nitrogen atom was located close to

Table 3 Calculated adsorption energy $\left(E_{\text {ads }}\right)$, deformation energy for the molecule $\left(E_{\mathrm{mol}}^{\text {deform}}\right)$ and the aluminum slab ( $\left.E_{\mathrm{slab}}^{\text {deform}}\right)$, vdW energy $\left(E_{\mathrm{vdw}}\right)$, interaction energy $\left(E_{\text {int }}\right)$, charge variation on the molecule $\left(\Delta Q_{\text {tot }}^{\mathrm{mol}}\right)$ for the 8-HQ molecule and its derivatives adsorbed on the Al(111) surface and work function variation $(\Delta \phi)$ upon adsorption. $(\varphi)$ : physisorbed $\alpha 8-\mathrm{HQ}$ molecule; $(\chi 1)$ and $(\chi 2)$ : chemisorbed $\alpha$ 8-HQ molecule; $(\tau 1)$ and $(\tau 2)$ : chemisorbed tautomer; $(\delta 1),(\delta 2)$ and $(\delta 3)$ : chemisorbed dehydrogenated 8-HQ molecule; $(\eta)$ : chemisorbed hydrogenated 8-HQ molecule

\begin{tabular}{|c|c|c|c|c|c|c|c|}
\hline Configuration & $\begin{array}{l}E_{\mathrm{ads}} \\
(\mathrm{eV})\end{array}$ & $\begin{array}{l}E_{\mathrm{mol}}^{\text {deform }} \\
(\mathrm{eV})\end{array}$ & $\begin{array}{l}E_{\text {slab }}^{\text {deform }} \\
(\mathrm{eV})\end{array}$ & $\begin{array}{l}E_{\mathrm{vdW}} \\
(\mathrm{eV})\end{array}$ & $\begin{array}{l}E_{\text {int }} \\
(\mathrm{eV})\end{array}$ & $\begin{array}{l}\Delta Q_{\mathrm{tot}}^{\mathrm{mol}} \\
\text { (e) }\end{array}$ & $\begin{array}{l}\Delta \phi \\
(\mathrm{eV})\end{array}$ \\
\hline \multicolumn{8}{|l|}{$\alpha 8-H Q$} \\
\hline$\varphi$ & -0.90 & 0.01 & 0.01 & -1.05 & -0.92 & -0.20 & -0.23 \\
\hline$\chi 1$ & -0.86 & 1.41 & 0.10 & -1.22 & -2.37 & -1.33 & -0.19 \\
\hline$\chi^{2}$ & -1.11 & 1.60 & 0.14 & -1.27 & -2.85 & -1.33 & -0.16 \\
\hline \multicolumn{8}{|l|}{ Tautomer } \\
\hline$\tau 1$ & -2.16 & 2.15 & 0.23 & -1.21 & -4.54 & -1.54 & -0.20 \\
\hline$\tau 2$ & -2.39 & 2.27 & 0.24 & -1.27 & -4.90 & -1.46 & -0.19 \\
\hline \multicolumn{8}{|c|}{ Dehydrogenated 8-HQ } \\
\hline$\delta 1$ & -3.27 & 1.90 & 0.66 & -1.11 & -5.83 & -2.16 & -0.16 \\
\hline$\delta 2$ & -3.40 & 1.72 & 0.23 & -1.26 & -5.35 & -1.99 & -0.01 \\
\hline$\delta 3$ & -3.45 & 0.55 & 0.43 & -0.77 & -4.43 & -1.17 & -0.60 \\
\hline \multicolumn{8}{|c|}{ Hydrogenated 8-HQ } \\
\hline$\eta$ & -1.71 & 0.69 & 0.10 & -1.24 & -2.50 & -0.72 & -0.36 \\
\hline
\end{tabular}

a threefold site. This geometry was close to that obtained by Zhang et al. ${ }^{48}$ for 8-HQ adsorbed on the $\mathrm{Cu}(111)$ surface.

3.2.2 Chemisorption. Two chemisorbed configurations were obtained for the $\alpha$ 8-HQ molecule and they are denoted $\chi 1$ and $\chi_{2}$ in Table 3 and on Fig. 3. In the $\chi 1$ configuration, the $L$-axis of the molecule was orientated along the $[0 \overline{2} 2]$ direction. The $\mathrm{O}$ and $\mathrm{N}$ atoms were located on top of $\mathrm{Al}$ surface atoms and $\mathrm{C}_{2}$ atom was located close to a top site. In the $\chi^{2}$ configuration, the short axis ( $S$-axis, through $\mathrm{N}_{\text {and }} \mathrm{C}_{4}$ atoms, see Fig. 1) of the molecule was oriented along the $[\overline{2} 20]$ direction and the $L$-axis was oriented along $[0 \overline{2} 2]$ direction. The $\mathrm{O}, \mathrm{N}$ and $\mathrm{C}_{4}$ atoms were located on top of $\mathrm{Al}$ surface atoms. The calculated adsorption energy $\left(E_{\mathrm{ads}}\right)$, deformation energy for the molecule $\left(E_{\mathrm{mol}}^{\mathrm{deform}}\right)$ and the substrate $\left(E_{\text {slab }}^{\text {deform }}\right)$ upon adsorption and the global charge variation on the adsorbate $\Delta Q_{\mathrm{tot}}^{\mathrm{mol}}$ are summarized in Table 3. The calculated adsorption energies of the $\chi 1$ and $\chi_{2}$ were $-0.86 \mathrm{eV}$ and $-1.11 \mathrm{eV}$ respectively. These values were in the same range than for the physisorbed configuration. The main reason to get similar adsorption energy was that the deformation energy of the molecule in these two configurations was $1.50 \pm 0.10 \mathrm{eV}$, which reduced significantly the chemisorption energy to a value close to that of the physisorption. If we subtracted the deformation energy to the adsorption energy, we obtained an interaction energy $\left(E_{\text {int }}\right)$ between the molecule and the metal of $-2.37 \mathrm{eV}$ and $-2.85 \mathrm{eV}$ for the $\chi^{1}$ and $\chi^{2}$ configurations respectively whereas the interaction energy for the physisorbed mode was $-0.92 \mathrm{eV}$. This showed a strong molecule/surface interaction for $\chi 1$ and $\chi^{2}$ configurations. The $\mathrm{vdW}$ energy in these chemisorbed $\alpha$ 8-HQ configurations was $-1.24 \pm 0.03 \mathrm{eV}$ showing again a high contribution of the $\mathrm{vdW}$ forces to the molecule-surface interactions. Due to the high value of deformation energies, a calculation without vdW corrections gave a positive adsorption energy of $+0.07 \mathrm{eV}$ for $\chi 2$ configuration, in spite of the formation of chemical bonds between 8-HQ and the substrate.

For the $\chi_{1}$ and $\chi^{2}$ configurations, the carbon ring was not much deformed (variation of $\mathrm{C}-\mathrm{C}$ distances $<0.03 \AA$, in Table 1 and planar phenolic ring in Fig. 3). The main geometrical changes on the molecule concerned the pyridine ring and specially the bonds involving $\mathrm{N}, \mathrm{C}_{2}$ or $\mathrm{C}_{4}$ atoms (see Table 1). Moreover these two cycles (phenolic and pyridine) were not any longer coplanar. This high deformation of the molecule, due to the adsorption was directly linked to the electronic transfer from the substrate to the molecule (1.33 electrons) that modified the electronic density on the cycles. The analysis of the charge variation on the atoms (in Table 5) showed that the transferred electrons were mainly localized on these $\mathrm{N}, \mathrm{C}_{2}$ and $\mathrm{C}_{4}$ atoms. The electronic transfer came from the $\mathrm{Al}$ atoms that bound directly with the molecule, i.e. $\mathrm{Al}_{2}(\Delta Q=+0.47 \mathrm{e}$, bound to $\mathrm{N}), \mathrm{Al}_{3}\left(\Delta Q=+0.47 \mathrm{e}\right.$, bound to $\left.\mathrm{C}_{2}\right)$ for the $\chi 1$ configuration and $\mathrm{Al}_{2}(\Delta Q=+0.63$ e, bound to $\mathrm{N}), \mathrm{Al}_{4}(\Delta Q=$ +0.55 e, bound to $\mathrm{C}_{4}$ ) for the $\chi 2$ configuration (see Table 6 ). The charge calculation also showed an electronic transfer from the $\mathrm{Al}_{1}$ atom (below the $\mathrm{O}$ atom) to the molecule, with a value of +0.47 e and +0.21 e net charge for the $\chi_{1}$ and $\chi^{2}$ configurations respectively. This $\mathrm{Al}_{1}$ atom moved slightly out of the surface. 

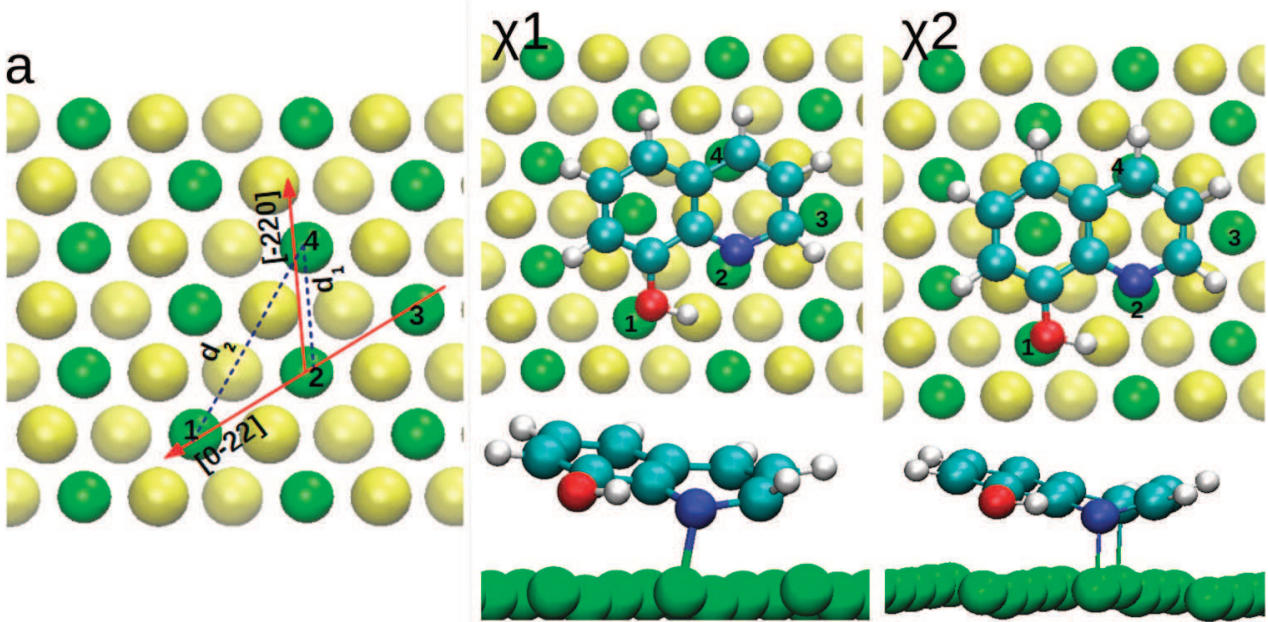

$\varphi$

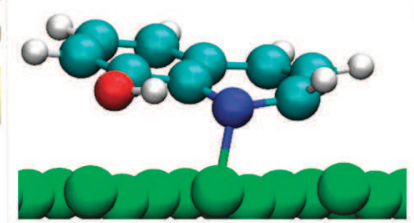

T2

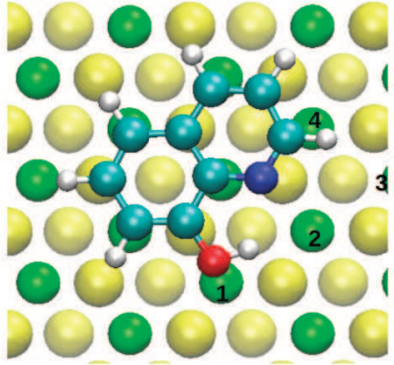

$\tau 1$ 00000000000000

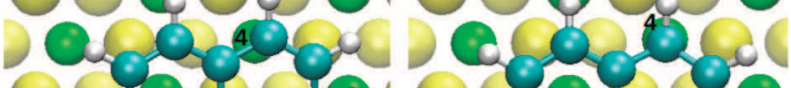
0.90103109083

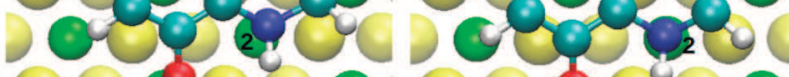
00190001000000 1000000000000
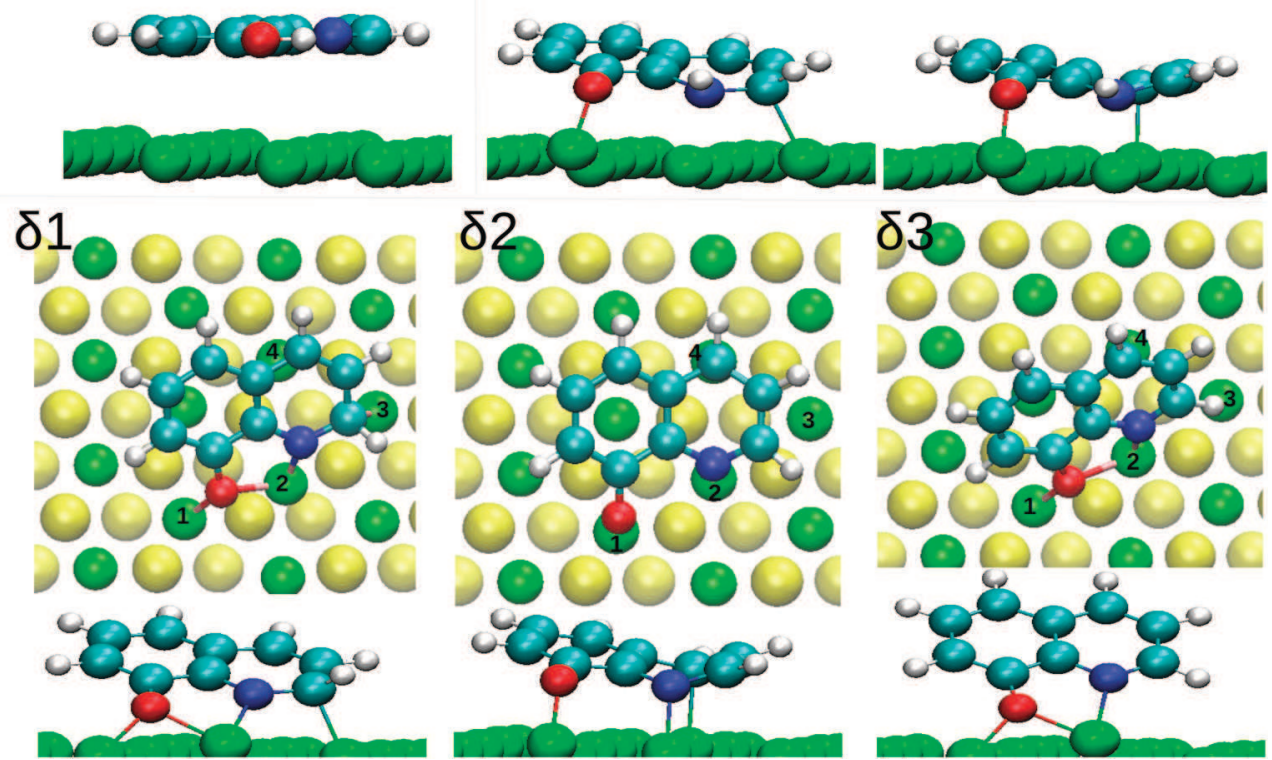

\section{$\delta 2$}
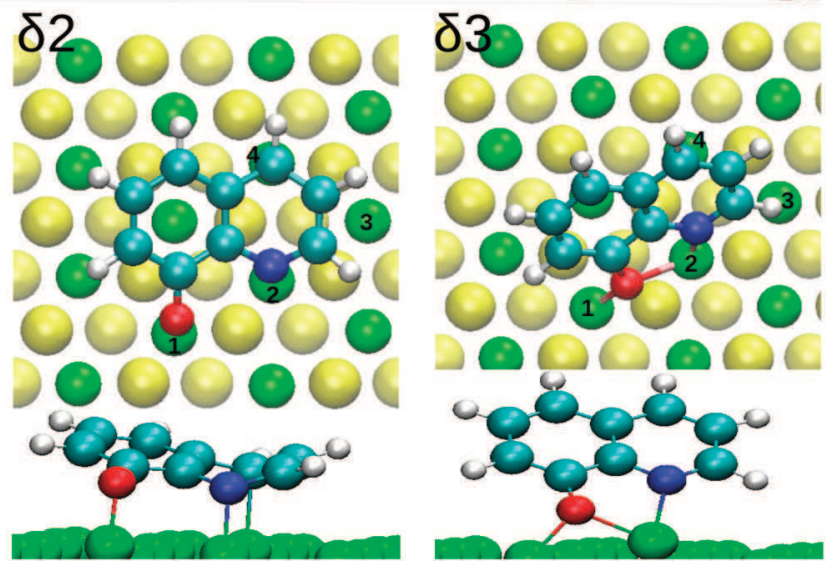

Fig. $3 \propto$ 8-HQ, tautomer and dehydrogenated 8-HQ topologies on Al(111). (a) Schematic presentation of short bridge $\left(d_{1}\right)$, long bridge $\left(d_{2}\right)$ on the Al(111) surface and crystallographic orientations. Green spheres: Al surface atoms; yellow spheres: Al sub-surface atoms. Top and side views of optimized structures; $(\varphi),(\chi 1)$ and $(\chi 2)$ : physisorbed and chemisorbed modes for the 8-HQ molecule; $(\tau 1)$ and $(\tau 2)$ : chemisorbed modes for the tautomer; $(\delta 1),(\delta 2)$ and $(\delta 3)$ : chemisorbed modes for the dehydrogenated $8-\mathrm{HQ}$ molecule.

It could be surprising as we will demonstrate below that the $\mathrm{O}$ atom was not chemically bound to the surface in $\alpha$ 8-HQ adsorption (see distance $\mathrm{Al}_{1}-\mathrm{O}$ and plotting of $\Delta \rho$ in Fig. 4). In fact, there was a global electronic rearrangement and a charge redistribution within the atoms of the $\alpha$ 8-HQ molecule that followed the electronic transfer from the surface. Moreover in these two configurations, the charge variation on the $\mathrm{Al}$ atoms others than that directly bound to the molecule were less than \pm 0.10 e and the participation of these atoms to the bonding could be considered as negligible. All these results showed that the $\chi_{1}$ and $\chi_{2}$ configurations of the $\alpha$ 8-HQ molecule were chemisorbed modes. It was also evident on the plotting of the 

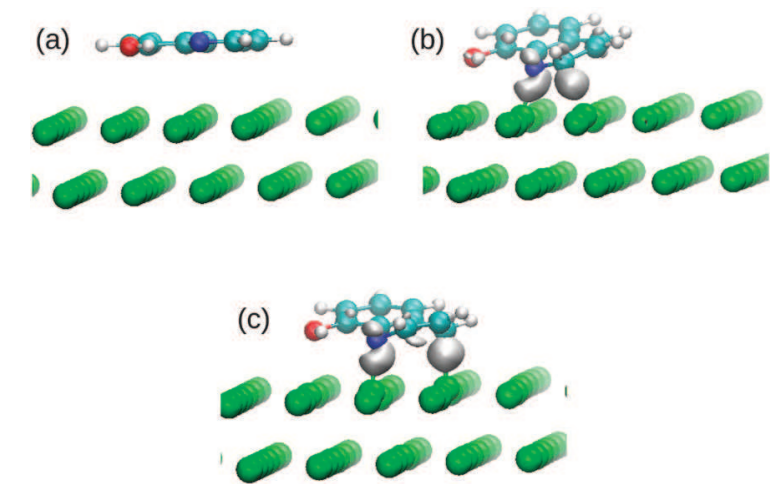

Fig. 4 Charge distribution variation $\Delta \rho$ for the $\alpha$ 8-HQ molecule adsorbed on the $\mathrm{Al}(111)$ surface (isosurface value: -0.002 e $\AA^{-3}$ ); (a) $\varphi$ configuration; (b) $\chi 1$ configuration; (c) $\chi 2$ configuration.

charge distribution variation $\Delta \rho$ (see Fig. 4), that electrons were shared between the surface $\mathrm{Al}$ atoms and the $\mathrm{N}$ and $\mathrm{C}_{2}$ atoms for the $\chi 1$ configuration and between the $\mathrm{Al}$ surface atoms and the $\mathrm{N}$ and $\mathrm{C}_{4}$ atoms for the $\chi^{2}$ configuration. The $\mathrm{Al}_{2}-\mathrm{N}$ and $\mathrm{Al}_{3}-\mathrm{C}_{2}\left(\mathrm{Al}_{4}-\mathrm{C}_{4}\right)$ distances in Table 4 for the $\chi 1(\chi 2)$ configurations were $1.96 \pm 0.01 \AA$, and $2.23 \pm 0.04 \AA$, respectively. The $\mathrm{Al}_{2}-\mathrm{N}$ bond length was in agreement with the $\mathrm{Al}-\mathrm{N}$ bond length $(2.02 \AA)$ calculated by Arrouvel et $a .^{41}$ in their study of the chemisorption of glycine on $\alpha$-alumina and with the Al-N bond length (1.98 to $2.05 \AA$ ) calculated by Borck et al. ${ }^{40}$ in their work about the adsorption of methylamine on $\alpha$-alumina. Same feature was found for the tautomer and the dehydrogenated molecules as it is described below. The aluminum/molecule chemical bonding for all these molecules and the creation of $\mathrm{Al}_{2}-\mathrm{N}$ and $\mathrm{Al}_{3}-\mathrm{C}_{2}$ or $\mathrm{Al}_{4}-\mathrm{C}_{4}$ bonds could be explained by the position of the $\mathrm{C}_{2}$ and $\mathrm{C}_{4}$ atoms, that are in ortho or para positions relatively to the $\mathrm{N}$ atom. These positions are known as

Table 4 Bond lengths (in $\AA$ ) between oxygen $\left(d_{\mathrm{AlO}}\right)$, nitrogen $\left(d_{\mathrm{AIN}}\right)$, carbon atoms $\left(d_{\mathrm{AlC}_{2}}, d_{\mathrm{AlC}_{4}}\right)$ and nearest surface aluminum atoms; short $\Delta d_{1}$ and large $\Delta d_{2}$ bridge variations; buckling $(\Delta h)$ along the surface normal direction; $(\varphi)$ : physisorbed $\alpha$ 8-HQ molecule; $(\chi 1)$ and $(\chi 2)$ : chemisorbed $\alpha$ $8-\mathrm{HQ}$ molecule; $(\tau 1)$ and $(\tau 2)$ : chemisorbed tautomer; $(\delta 1),(\delta 2)$ and $(\delta 3)$ : chemisorbed dehydrogenated $8-\mathrm{HQ}$ molecule; $(\eta)$ : chemisorbed hydrogenated $8-\mathrm{HQ}$ molecule. Al-Al distances for the clean relaxed slab: $d_{1}=2.86 \AA$, and $d_{2}=4.95 \AA$

\begin{tabular}{|c|c|c|c|c|c|c|c|}
\hline \multicolumn{8}{|c|}{$\frac{\text { Configur }}{\alpha 8-\mathrm{HQ}}$} \\
\hline$\varphi$ & 3.09 & 3.41 & 3.28 & 3.16 & 0.00 & 0.00 & 0.09 \\
\hline$\chi 1$ & 2.33 & 1.95 & 2.27 & 3.02 & 0.13 & 0.05 & 0.22 \\
\hline$\chi^{2}$ & 2.43 & 1.97 & 2.94 & 2.19 & 0.19 & 0.14 & 0.31 \\
\hline \multicolumn{8}{|c|}{ Tautomer } \\
\hline$\tau 1$ & 1.83 & 2.13 & 2.20 & 3.20 & 0.03 & 0.08 & 0.52 \\
\hline$\tau 2$ & 1.81 & 2.23 & 3.15 & 2.18 & 0.09 & 0.19 & 0.52 \\
\hline \multicolumn{8}{|c|}{ Dehydrogenated 8-HQ } \\
\hline$\delta 1$ & 1.91 & 1.90 & 2.14 & 3.44 & 0.62 & 0.11 & 0.64 \\
\hline$\delta 2$ & 1.80 & 1.92 & 2.84 & 2.20 & 0.26 & 0.22 & 0.34 \\
\hline$\delta 3$ & 1.92 & 2.05 & 3.37 & 4.71 & 0.13 & 0.00 & 0.81 \\
\hline \multicolumn{8}{|c|}{ Hydrogenated 8-HQ } \\
\hline$\eta$ & 3.02 & 2.31 & 3.28 & 2.17 & 0.07 & 0.07 & 0.35 \\
\hline
\end{tabular}

more electrophile positions on the pyridine molecule than the meta position. ${ }^{66}$ The electronic transfer from the surface to the molecule was thus particularly directed to these $\mathrm{C}_{2}$ and $\mathrm{C}_{4}$ atoms.

We focus now on the tautomer species. According to calculations on the free molecules, the tautomer could be more reactive than the $\alpha$ 8-HQ because of its smaller HOMO-LUMO gap. Two chemisorbed configurations were found ( $\tau 1$ and $\tau 2$ configurations in Table 3 and Fig. 3 ). In the $\tau 1$ configuration, the tautomer was chemisorbed on neighboring top sites via $\mathrm{N}$ and $\mathrm{O}$ atoms, and on almost bridge site via $\mathrm{C}_{2}$ atom, with $L$-axis oriented along the $[0 \overline{2} 2]$ direction. The adsorption energy of this $\tau 1$ configuration was $-2.16 \mathrm{eV}$, which was significantly stronger than the $\chi^{2}$ configuration of the $\alpha 8$ - HQ by $1.05 \mathrm{eV}$. However, the deformation energy was also larger (2.15 eV $>1.60 \mathrm{eV}$ for the most stable chemisorbed $\alpha$ 8-HQ). As shown in Fig. 3 ( $\tau 1$ configuration), the tautomer was bound to surface aluminum atoms by the $\mathrm{O}, \mathrm{N}$ and $\mathrm{C}_{2}$ atoms with $\mathrm{Al}_{1}-\mathrm{O}, \mathrm{Al}_{2}-\mathrm{N}$ and $\mathrm{Al}_{3}-\mathrm{C}_{2}$ distances of $1.83 \AA$, $2.13 \AA$, and $2.20 \AA$, respectively (see Table 4). Upon adsorption the carbon cycle was only slightly deformed as in the case of chemisorbed $\alpha$ 8-HQ and the $\mathrm{C}_{i}-\mathrm{C}_{j}(i, j=5$ to 10$)$ distances changed of less than $0.02 \AA$, except for the $\mathrm{C}_{8}-\mathrm{C}_{9}$ bond that was close to the $\mathrm{O}$ and $\mathrm{N}$ atoms involved in the bonding. The high value of the deformation energy of the molecule seemed to be linked to larger modifications of the pyridine ring, due to bonds involving $\mathrm{N}$ and $\mathrm{C}_{2}$ atoms: in the $\alpha 8-\mathrm{HQ}$, during the adsorption process, the $\mathrm{O}-\mathrm{C}_{8}$, $\mathrm{C}_{8}-\mathrm{C}_{9}, \mathrm{C}_{9}-\mathrm{N}$, and $\mathrm{C}_{2}-\mathrm{N}$ bonds lengths were modified by $+0.05 \AA$, $-0.03 \AA,+0.05 \AA$, and $+0.10 \AA$, respectively (see $\chi^{2}$ in Table 1 ) whereas for the tautomer $(\tau 1)$ adsorption these distances were modified by $+0.07 \AA,-0.05 \AA,+0.10 \AA$, and $+0.17 \AA$, respectively. The Bader analysis showed that 1.54 electrons were transferred from the substrate to the tautomer. This confirmed that the tautomer is a better electron acceptor than the $\alpha$ 8-HQ. Again the electronic transfers presented in Table 5 showed a gain of electrons for the $\mathrm{O}, \mathrm{C}_{8}, \mathrm{C}_{9}$, and $\mathrm{C}_{2}$ atoms for which the bond distances were modified and there was only a slight variation of the charge on the $\mathrm{N}$ atom. The values of the net charge variation on each $\mathrm{Al}$ atoms are summarized in Table 6. The electronic transfer came from the $\mathrm{Al}$ surface atoms bound to $\mathrm{O}, \mathrm{N}$ and $\mathrm{C}_{2}$ atoms of the molecule. We thus conclude that an electronic redistribution within the molecule followed the electrons transfer from the substrate to the adsorbate.

The stable $\tau 2$ configuration had its $S$-axis along the [220] orientation, and the $L$-axis along the [0ㄹ2] direction. The $\mathrm{N}, \mathrm{O}$ and $\mathrm{C}_{4}$ were on top of $\mathrm{Al}$ surface atoms, with an adsorption energy of $-2.39 \mathrm{eV}(0.23 \mathrm{eV}$ lower than the $\tau 1$ configuration). In this configuration, the molecular deformation energy was similar to the $\tau 1$ configuration, but the optimized geometry showed clearly an $\mathrm{Al}_{4}-\mathrm{C}_{4}(2.18 \AA)$ bond, instead of the $\mathrm{Al}_{3}-\mathrm{C}_{2}$ $(2.20 \AA)$ bond that was in $\tau 1$ configuration. The pyridine ring was deformed with all the distances modified of 0.03 to $0.10 \AA$, and the molecule was again not planar (see Fig. 3). The global electrons transfer from the substrate to the molecule (1.46 electrons) was similar to that of $\tau 1$ configuration. But in the $\tau 2$ configuration the $\mathrm{C}_{4}$ atom also gained electrons $\left(\Delta Q_{\mathrm{C}_{4}}=-0.39 \mathrm{e}\right)$ and the transfer 
Table 5 Charge variation $\Delta Q_{x}$ (in e) on atom $x$ of the molecules after adsorption on the Al(111) surface (Bader analysis)

\begin{tabular}{|c|c|c|c|c|c|c|c|c|c|c|c|c|}
\hline & $\mathrm{C}_{2}$ & $\mathrm{C}_{3}$ & $\mathrm{C}_{4}$ & $\mathrm{C}_{5}$ & $\mathrm{C}_{6}$ & $\mathrm{C}_{7}$ & $\mathrm{C}_{8}$ & $\mathrm{C}_{9}$ & $\mathrm{C}_{10}$ & $\mathrm{~N}$ & $\mathrm{O}$ & $\mathrm{H}$ \\
\hline \multicolumn{13}{|c|}{$\alpha 8-\mathrm{HQ}$} \\
\hline$\chi 1$ & -0.75 & -0.08 & +0.06 & -0.14 & -0.01 & -0.17 & -0.09 & -0.09 & +0.12 & -0.20 & -0.09 & +0.01 \\
\hline$\chi^{2}$ & -0.42 & -0.09 & -0.30 & -0.07 & +0.00 & -0.17 & -0.14 & -0.08 & +0.09 & -0.24 & -0.02 & -0.06 \\
\hline \multicolumn{13}{|c|}{ Tautomer } \\
\hline$\tau 1$ & -0.69 & -0.09 & -0.02 & +0.15 & -0.04 & -0.02 & -0.31 & -0.35 & +0.00 & +0.07 & -0.21 & -0.05 \\
\hline$\tau 2$ & -0.31 & +0.10 & -0.39 & +0.16 & -0.12 & +0.03 & -0.29 & -0.31 & -0.07 & +0.02 & -0.20 & -0.05 \\
\hline \multicolumn{13}{|c|}{ Dehydrogenated 8-HQ } \\
\hline$\delta 1$ & -0.69 & -0.09 & -0.02 & +0.15 & -0.04 & -0.02 & -0.31 & -0.35 & +0.00 & +0.07 & -0.21 & - \\
\hline$\delta 2$ & -0.31 & +0.10 & -0.39 & +0.16 & -0.12 & +0.03 & -0.29 & -0.31 & -0.07 & +0.02 & -0.20 & - \\
\hline$\delta 3$ & -0.14 & +0.07 & +0.05 & -0.08 & -0.11 & +0.12 & -0.49 & -0.25 & +0.25 & -0.28 & -0.42 & - \\
\hline \multicolumn{13}{|c|}{ Hydrogenated 8-HQ } \\
\hline$\eta$ & -0.07 & -0.26 & -0.33 & -0.20 & +0.24 & -0.12 & +0.01 & -0.04 & -0.04 & -0.06 & -0.05 & +0.01 \\
\hline
\end{tabular}

Table 6 Charge variation $\Delta Q_{x}$ (in e) on Al atoms of the surface after adsorption (Bader analysis). Al ( $x$, mode): Al atom bound to the $x$ atom of the molecule in a mode geometry

\begin{tabular}{|c|c|c|c|c|}
\hline & $\mathrm{Al}_{1}$ & $\mathrm{Al}_{2}$ & $\mathrm{Al}_{3}$ & $\mathrm{Al}_{4}$ \\
\hline \multicolumn{5}{|c|}{$\alpha 8-H Q$} \\
\hline$\chi 1$ & +0.47 & +0.47 (N, top) & $+0.47\left(\mathrm{C}_{2}\right.$, almost top $)$ & +0.03 \\
\hline$\chi^{2}$ & +0.21 & $+0.63(\mathrm{~N}$, top $)$ & +0.03 & $+0.55\left(\mathrm{C}_{4}\right.$, top $)$ \\
\hline \multicolumn{5}{|c|}{ Tautomer } \\
\hline$\tau 1$ & $+0.75(\mathrm{O}$, top $)$ & $+0.38(\mathrm{~N}$, top $)$ & $+0.57\left(\mathrm{C}_{2}\right.$, almost top $)$ & -0.02 \\
\hline$\tau 2$ & $+0.73(\mathrm{O}$, top $)$ & $+0.32(\mathrm{~N}$, top $)$ & 0.00 & $+0.58\left(\mathrm{C}_{4}\right.$, top $)$ \\
\hline \multicolumn{5}{|c|}{ Dehydrogenated 8-HQ } \\
\hline$\delta 1$ & $+0.53(\mathrm{O}$, bridge $)$ & +1.06 (O and $\mathrm{N}$, bridge $)$ & $+0.56\left(\mathrm{C}_{2}\right.$, top $)$ & +0.01 \\
\hline$\delta 2$ & $+0.76(\mathrm{O}$, top $)$ & $+0.62(\mathrm{~N}$, top $)$ & +0.06 & $+0.55\left(\mathrm{C}_{4}\right.$, top $)$ \\
\hline$\delta 3$ & +0.49 (O, bridge $)$ & +0.89 ( $\mathrm{O}$ and $\mathrm{N}$, bridge $)$ & -0.09 & 0.00 \\
\hline \multicolumn{5}{|c|}{ Hydrogenated 8-HQ } \\
\hline$\eta$ & +0.00 & $+0.34(\mathrm{~N}$, top $)$ & -0.00 & $+0.59\left(\mathrm{C}_{4}\right.$, top $)$ \\
\hline
\end{tabular}

to the $\mathrm{C}_{2}$ atom was lower $\left(\Delta Q_{\mathrm{C}_{2}}=-0.31\right.$ e) than in the $\tau 1$ configuration $\left(\Delta Q_{\mathrm{C}_{2}}=-0.69 \mathrm{e}\right)$. The electronic transfer came from the aluminum surface below $\mathrm{O}, \mathrm{N}$ and $\mathrm{C}_{4}$ atoms (see Table 6) and was again followed by a redistribution within the molecule. For these two chemisorbed configurations, $\Delta \rho$ plots (see Fig. $5 \Delta \rho=-0.002$ e $\AA^{-3}$ ) showed clearly electron accumulation regions between the molecules and the $\mathrm{Al}$ surface atoms involved in bonding. This strong molecule/metal coupling was confirmed by the interaction energy of $-4.54 \mathrm{eV}$ and $-4.90 \mathrm{eV}$ for the $\tau 1$ and $\tau 2$ configurations respectively. The average vdW contribution in these two configurations was $-1.24 \pm 0.03 \mathrm{eV}$ which accounted for about one forth of the interaction energy. Finally as in the case of the $\alpha$ 8-HQ molecule, the coordination

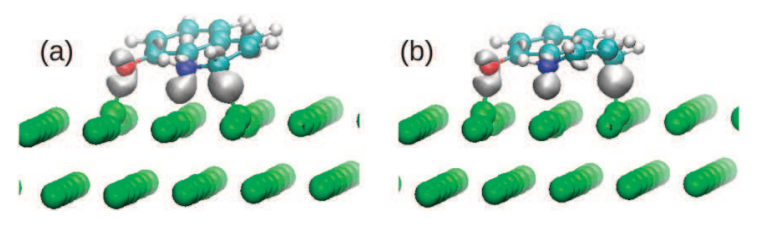

Fig. 5 Charge distribution variation $\Delta \rho$ for the tautomer molecule chemisorbed on the Al(111) surface (isosurface value: -0.002 e $\AA^{-3}$ ); (a) $\tau 1$ configuration; (b) $\tau 2$ configuration. of the tautomer molecule to the surface was done via the $\mathrm{C}_{2}$ and $\mathrm{C}_{4}$ atoms that are the most electrophile positions on the pyridine ring.

Starting from several initial geometries, the dehydrogenated 8-HQ molecule chemisorbed on the $\mathrm{Al}(111)$ surface in three stable configurations with different chemical bonding characteristics and molecule orientations relatively to the surface. They are denoted $\delta 1, \delta 2$ and $\delta 3$ in Fig. 3. The adsorption energies were $-3.27 \mathrm{eV},-3.40 \mathrm{eV}$ and $-3.45 \mathrm{eV}$ respectively (in Table 3 ). The $\delta 2$ and $\delta 3$ configurations were more stable than the $\delta 1$ configuration by at least $+0.13 \mathrm{eV}$. The $L$-axis of the three configurations were all oriented along the $[0 \overline{2} \overline{2}]$ direction (Fig. 3), while only the $\delta 2$ configuration had its $S$-axis oriented along the $[\overline{2} 20]$ direction. The $\mathrm{Al}-\mathrm{X}\left(\mathrm{X}=\mathrm{O}, \mathrm{N}, \mathrm{C}_{2}\right.$ and $\left.\mathrm{C}_{4}\right)$ bond lengths given in Table 4 were typical chemical bond lengths.

The deformation energy of the most stable $\delta 3$ configuration was much smaller than the deformation energy for the $\delta 1$ and $\delta 2$ configurations $(0.55 \mathrm{eV}, 1.72 \mathrm{eV}$ and $1.90 \mathrm{eV}$ for $\delta 3, \delta 2$ and $\delta 1$ respectively). The low deformation energy for $\delta 3$ could be explained by the absence of bonding between the carbon atoms of the pyridine ring and aluminum surface atoms unlike in $\delta 1$ and $\delta 2$ configurations. Thus, the pyridine ring remained planar, but not parallel to the $\mathrm{Al}$ surface (Fig. 3) even if put initially 
parallel and far from the surface. Only the lengths of the bonds close to the $\mathrm{O}$ and $\mathrm{N}$ atoms were modified $\left(\Delta d_{\mathrm{C}_{7} \mathrm{C}_{8}}=-0.06 \AA\right.$, $\Delta d_{\mathrm{C}_{8} \mathrm{C}_{9}}=-0.06 \AA, \Delta d_{\mathrm{C}_{9} \mathrm{~N}}=+0.03 \AA$, and $\left.\Delta d_{\mathrm{C}_{8} \mathrm{O}}=+0.12 \AA\right)$. The vdW contribution was also lower than in the other configurations because the molecule was not parallel at all to the $\mathrm{Al}$ surface. This reduced significantly the molecule-surface dispersion interactions compared to configurations where the molecule was almost parallel to the surface. In the same time, the electronic transfer from the substrate to the molecule was also the lowest one (1.17 electrons), which could also be explained by the absence of $\mathrm{Al}-\mathrm{C}$ bond between the molecule and the substrate. For $\delta 3$, the atoms that had the largest change of their net charge during the adsorption process were $\mathrm{N}, \mathrm{O}, \mathrm{C}_{8}$ and $\mathrm{C}_{9}$ atoms $\left(\Delta Q_{\mathrm{N}}=-0.28 \mathrm{e}\right.$, $\Delta Q_{\mathrm{O}}=-0.42 \mathrm{e}, \Delta Q_{\mathrm{C}_{8}}=-0.49 \mathrm{e}$, and $\left.\Delta Q_{\mathrm{C}_{9}}=-0.25 \mathrm{e}\right)$. Most of the electronic transfer came from the $\mathrm{Al}_{1}$ and $\mathrm{Al}_{2}$ atoms of the aluminum surface. Their net charge variations due to the adsorption of the molecule are given in Table 6 . The $\mathrm{Al}_{2}$ atom was shared between the $\mathrm{N}$ atom that was adsorbed on top and the $\mathrm{O}$ atom that was adsorbed in a bridge position between $\mathrm{Al}_{1}$ and $\mathrm{Al}_{2}$. The $\mathrm{Al}_{2}$ atom thus gave globally more electrons than the $\mathrm{Al}_{1}$ atom $\left(\Delta Q_{\mathrm{Al}_{1}}=+0.49\right.$ e and $\left.\Delta Q_{\mathrm{Al}_{2}}=+0.89 \mathrm{e}\right)$.

The $\delta 1$ configuration corresponds to the molecule chemisorbed on the $\mathrm{Al}$ surface via the $\mathrm{O}$ atom (bridge site), $\mathrm{N}$ atom (almost top site) and the $\mathrm{C}_{2}$ atom (top site). The $\delta 2$ configuration showed the same topology as the chemisorbed $\alpha 8$-HQ in $\chi^{2}$ configuration and the bonding was between $\mathrm{O}, \mathrm{N}, \mathrm{C}_{4}$ and $\mathrm{Al}$ surface atoms (see Fig. 3) on top sites. The calculated deformation energies in Table 3 and the distances given in Table 1 showed that the molecules adsorbed with one carbon atom of the pyridine ring $\left(\mathbf{C}_{2}\right.$ for $\delta 1, \mathbf{C}_{4}$ for $\left.\delta 2\right)$ were more deformed than in the $\delta 3$ configuration which was only bound by the $\mathrm{O}$ and $\mathrm{N}$ atoms. The high values of the deformation energies $(1.90 \mathrm{eV}$ and $1.72 \mathrm{eV}$ for the $\delta 1$ and $\delta 2$ configurations respectively) were due to the change in the bond lengths, valence angles and the out-plane deformation. In these configurations, eight of the twelve bonds in the molecule were largely modified. The modification of the bond lengths in the pyridine ring were however different in two cases: the shorter $\mathrm{C}-\mathrm{C}$ bond was $\mathrm{C}_{3}-\mathrm{C}_{4}$ $(d=1.362 \AA)$ for $\delta 1$ and $\mathrm{C}_{2}-\mathrm{C}_{3}(d=1.368 \AA)$ for $\delta 2$ with more electronic delocalization around the $\mathrm{N}$ atom $\left(\mathrm{C}_{2}-\mathrm{N}\right.$ and $\mathrm{C}_{9}-\mathrm{N}$ bond lengths were $1.407 \pm 0.001 \AA$ ), less ring deformation and a slightly lower deformation energy in the $\delta 2$ configuration than in the $\delta 1$ configuration. The phenolic and pyridine cycles were closer to the surface than in the $\delta 3$ configuration and the vdW energy interactions were stronger (vdW energy: $-1.11 \mathrm{eV}$ for $\delta 1$ and $-1.26 \mathrm{eV}$ for $\delta 2$ ). The analysis of the charge transfer variation on the atoms of the molecule in $\delta 1$ and $\delta 2$ configurations presented in Table 5 showed again that electronic transfer and bond lengths changes were in close relation. In these configurations, most of the atoms were concerned by the electrons redistribution that followed the electron transfer from the substrate. The $\mathrm{Al}$ atoms involved in this chemical bonding were the atoms directly in contact with the $\mathrm{N}, \mathrm{O}$ and $\mathrm{C}_{2}\left(\right.$ or $\left.\mathrm{C}_{4}\right)$ atoms $\left(\Delta Q_{\mathrm{Al}}\right.$ from +0.53 e to $+1.06 \mathrm{e}$, see Table 6$)$ and the $\mathrm{Al}$ atom shared by two atoms of the molecule were the most highly changed. The net charge variations on the other $\mathrm{Al}$ atoms of the aluminum slab were less than \pm 0.10 e with thus a negligible electronic transfer to the molecule.
For these three configurations, the interaction energy between the dehydrogenated molecule and the surface was very high $(-5.83 \mathrm{eV},-5.35 \mathrm{eV}$ and $-4.43 \mathrm{eV})$ showing that the molecule was strongly bound to the surface. The $\Delta \rho$ plots (see Fig. 6) again presented electron accumulation regions between the molecules and the $\mathrm{Al}$ surface atoms and made clear some covalent nature of the bonding. Finally if we compare with the $\alpha$ 8-HQ and tautomer molecules, the dehydrogenated 8-HQ molecule was the most reactive toward the $\mathrm{Al}(111)$ surface according to the adsorption energy and the highest electronic transfer from the substrate to the molecule.

The stable configuration for the adsorption of the hydrogenated 8-HQ molecule on the $\mathrm{Al}(111)$ surface was denoted $\eta$ in Tables 1 and 3-6. This stable chemisorbed configuration had the same orientation and similar adsorption topology to that obtained for the chemisorption of the 8-HQ molecule in the $\chi^{2}$ configuration (Fig. 3). The nitrogen and $\mathrm{C}_{4}$ carbon atoms of the pyridine ring were involved in the bonding of the hydrogenated molecule to the metallic substrate. This could be deduced from the value of the $d_{\mathrm{AlN}}$ and $d_{\mathrm{AlC}_{4}}$ bond lengths in Table 4 . The strong electron accumulation $(\Delta \rho$ in Fig. 7) between the $\mathrm{C}_{4}$ carbon atom and the $\mathrm{Al}_{4}$ aluminum atom of the surface accounted for a covalent bonding with a stronger bonding via the $\mathrm{C}_{4}$ atom than via the $\mathrm{N}$ atom. An electronic transfer was observed again from the substrate to the molecule with a total charge variation $\Delta Q_{\mathrm{tot}}^{\mathrm{mol}}=-0.72$ e on the hydrogenated species. This electronic transfer was the lowest one compared to all the chemisorbed cases (8-HQ, tautomer and dehydrogenated) and this behavior might be due to the high energy of its LUMO.

From the adsorption energies, it could be concluded that the hydrogenated species was more strongly bound to the substrate than the 8-HQ molecule $\left(E_{\text {ads }}=-1.71 \mathrm{eV}\right.$ for the $\eta$ configuration and $E_{\text {ads }}=-0.98 \pm 0.12 \mathrm{eV}$ for 8-HQ). But it could be deduced that this strong value of the chemisorption energy for the $\eta$ configuration was due to a low value of the deformation energy of the molecule $(0.69 \mathrm{eV})$. The interaction energy of $-2.50 \mathrm{eV}$ was in the same range than in the case of the 8-HQ molecule $\left(E_{\text {int }}=-2.37\right.$ to $\left.-2.85 \mathrm{eV}\right)$ and their reactivity was thus similar.

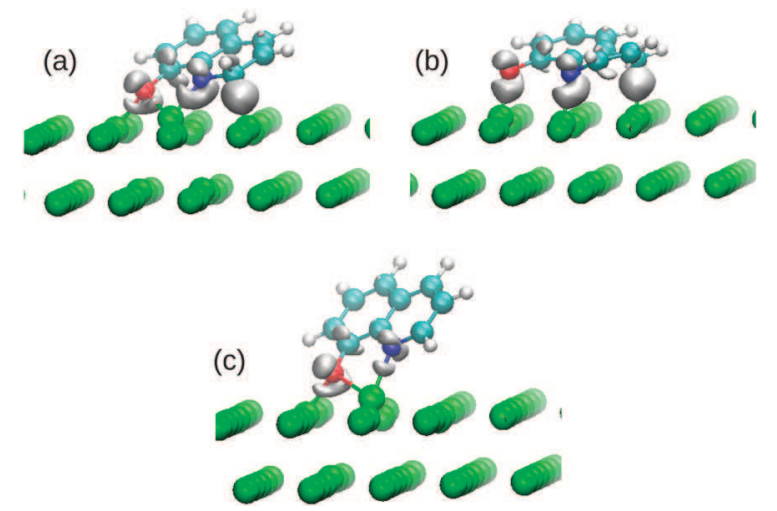

Fig. 6 Charge distribution variation $\Delta \rho$ for the dehydrogenated $8-\mathrm{HQ}$ molecule chemisorbed on the Al(111) surface (isosurface value: -0.002 e $\AA^{-3}$ ); (a) $\delta 1$ configuration; (b) $\delta 2$ configuration; (c) $\delta 3$ configuration. 


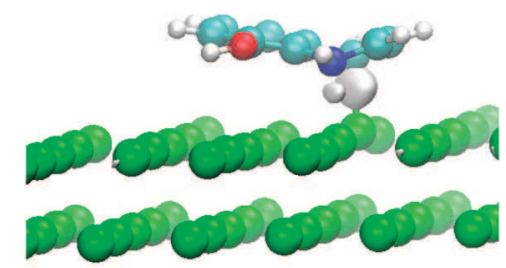

Fig. 7 Charge distribution variation $\Delta \rho$ for the hydrogenated $8-\mathrm{HQ}$ molecule chemisorbed on the $\mathrm{Al}(111)$ surface (isosurface value: -0.002 e $\AA^{-3}$ ); $\eta$ configuration.

3.2.3 Surface deformation during the chemisorption process. The deformation energy of the surface was in the range of $0.10-0.66 \mathrm{eV}$. It was linked to surface corrugation and lateral buckling in the Al surface plane. The adsorption induced vertical corrugation of the surface $(\Delta h)$ was measured as the difference in height between the highest and lowest $\mathrm{Al}$ atom in the surface layer. The extent of the lateral deformation of the short bridge site $\left(\Delta d_{1}\right)$ and the long bridge site $\left(\Delta d_{2}\right)$ was defined as the difference between the Al-Al distance of the short bridge $\left(d_{1}\right)$ site or the large bridge $\left(d_{2}\right)$ site after adsorption and the corresponding Al-Al distance on the clean relaxed surface. We chose to give the values of these $d_{1}$ and $d_{2}$ distances represented in Fig. 3(a) because they were the most modified $\mathrm{Al}-\mathrm{Al}$ distance on the $\mathrm{Al}(111)$ surface upon adsorption.

The corrugation of the $\mathrm{Al}(111)$ surface along the surface normal direction was characterized by $\Delta h$ distances of $0.22 \AA$, to $0.81 \AA$, (see chemisorbed modes in Table 4). When the molecules were adsorbed on top sites, the $\mathrm{Al}$ atoms were only bound to one atom of the molecule. The corrugation was thus lower $(\Delta h=0.22,0.52,0.34$ and $0.35 \AA$, for the $\chi 1$ to $\tau 2, \delta 2$ and $\eta$ configurations) and the deformation energy of the surface was smaller $(0.10,0.23,0.24$ and $0.10 \mathrm{eV}$ respectively). When the $\mathrm{O}$ and $\mathrm{N}$ atoms of the adsorbate occupied close sites on the $\mathrm{Al}(111)$ surface, they shared one $\mathrm{Al}$ atom such as in the $\delta 1$ and $\delta 3$ configurations and $\Delta h$ increased $(\Delta h=0.64 \AA$, for $\delta 1$ and $0.81 \AA$, for $\delta 2)$ as well as the surface deformation energy $(0.43 \mathrm{eV}$ and $0.66 \mathrm{eV}$ respectively). In addition to the surface corrugation, the adsorption process induced deformations in the $(x, y)$ surface plane. The largest changes in the distance between Al first neighbors were observed for the adsorption of the dehydrogenated 8-HQ molecule with a maximal $\Delta d_{1} / d_{1}$ change of $22 \%$ and again a high deformation energy. The maximal variation of the distance between $\mathrm{Al}$ second neighbors $\Delta d_{2} / d_{2}$ was less than $5 \%$ for all the configurations.

3.2.4 Work function changes. The work function $\phi$ is one of the most fundamental properties of a metallic surface. It is the minimum energy required to extract an electron out of the surface to the vacuum. As such, it is of interest to a wide range of surface phenomena. ${ }^{67-70}$ In particular the measurement of the work function changes $\Delta \phi$ is routinely used in the study of the adsorption processes on metal surfaces and photoemission. In this paper the work function was calculated from the difference between the Fermi energy $\left(E_{\mathrm{F}}\right)$ of the system and the average electrostatic potential energy $V_{\infty}$ in the middle of the vacuum region: $\phi=V_{\infty}-E_{\mathrm{F}}$.
The work function change induced by the adsorption of molecules on the metallic surface was thus calculated by: $\Delta \phi=\phi^{\prime}-\phi$, where $\phi^{\prime}$ and $\phi$ were the work function for the surface covered by molecules and the bare surface respectively, calculated with dipole correction.

In our case the adsorption of the $\alpha$ 8-HQ molecule and its derivatives at low coverage affected considerably the work function of the substrate and the work function change was in the range of -0.01 to $-0.60 \mathrm{eV}$ (see Table 3). This behavior of the work function variation is similar to that calculated experimentally and theoretically for the adsorption of the $\mathrm{Alq}_{3}$ complex on cobalt ${ }^{6,44}$ and aluminum ${ }^{47}$ surfaces. The adsorption of these organic molecules tended to decrease the work function of the $\mathrm{Al}(111)$ substrate and thus to modify the electronic surface properties of the substrate.

3.2.5 Electronic structure analysis. A more detailed picture of the molecule-surface bonding could be provided by an electronic structure analysis. Fig. 8 and 10 show the density of states projected onto the molecule for the 8-HQ molecule and the tautomer respectively, before and after adsorption on the $\mathrm{Al}(111)$ surface. For the dehydrogenated and hydrogenated 8-HQ molecule with an odd number of electrons, spin polarized (majority spin and minority spin) pDOS are presented in Fig. 11 and 12 respectively.

For the free molecules, in order to compare the relative reactivity of the $\alpha$ 8-HQ molecule and its derivatives with the aluminum surface, we plotted the pDOS of the 8-HQ, tautomer, dehydrogenated and hydrogenated 8-HQ molecules taking as $E_{\mathrm{F}}$ the Fermi level of the $\mathrm{Al}(111)$ clean slab. To do so a single point calculation was performed with the molecules at their optimized geometry (free molecules) and set parallel to the $\mathrm{Al}(111)$ surface at a vertical distance of $10 \AA$. We considered that this distance was large enough to prevent an interaction between the molecule and the metallic substrate. This condition was necessary to mimic the electronic structure of these molecules in their free state and we clearly identified the HOMO and LUMO of the molecule in the pDOS. By this approach (same reference, i.e. $E_{\mathrm{F}}$ of the aluminum slab in Fig. 8(a), 10(a), 11(a) and 12(a)), we could directly compare the reactivity of these three molecules with the $\mathrm{Al}(111)$ surface. The Al Fermi level was at the middle of HOMO-LUMO gap for the $\alpha$ 8-HQ molecule. For the tautomer the HOMO-LUMO gap was smaller, indicating again a high reactivity of the tautomer and specially a larger electron affinity than for the $\alpha$ 8-HQ as its LUMO was closer to the aluminum $E_{\mathrm{F}}$. The electronic structure for the dehydrogenated form of the 8-HQ molecule showed that the Fermi level of the metal was located just below the LUMO of the molecule. This indicated that the dehydrogenated molecule would interact spontaneously with the aluminum substrate. These features confirm the conclusion already reached by considering the energy of the HOMO and LUMO orbitals for the free molecules in section "Free 8-HQ molecule and derivatives". However by considering both the molecule and the substrate (at $10 \AA$, thus without interaction), this electronic structure analysis brings a new information on the reactivity, not only on the molecular point of view (HOMO-LUMO gap), 

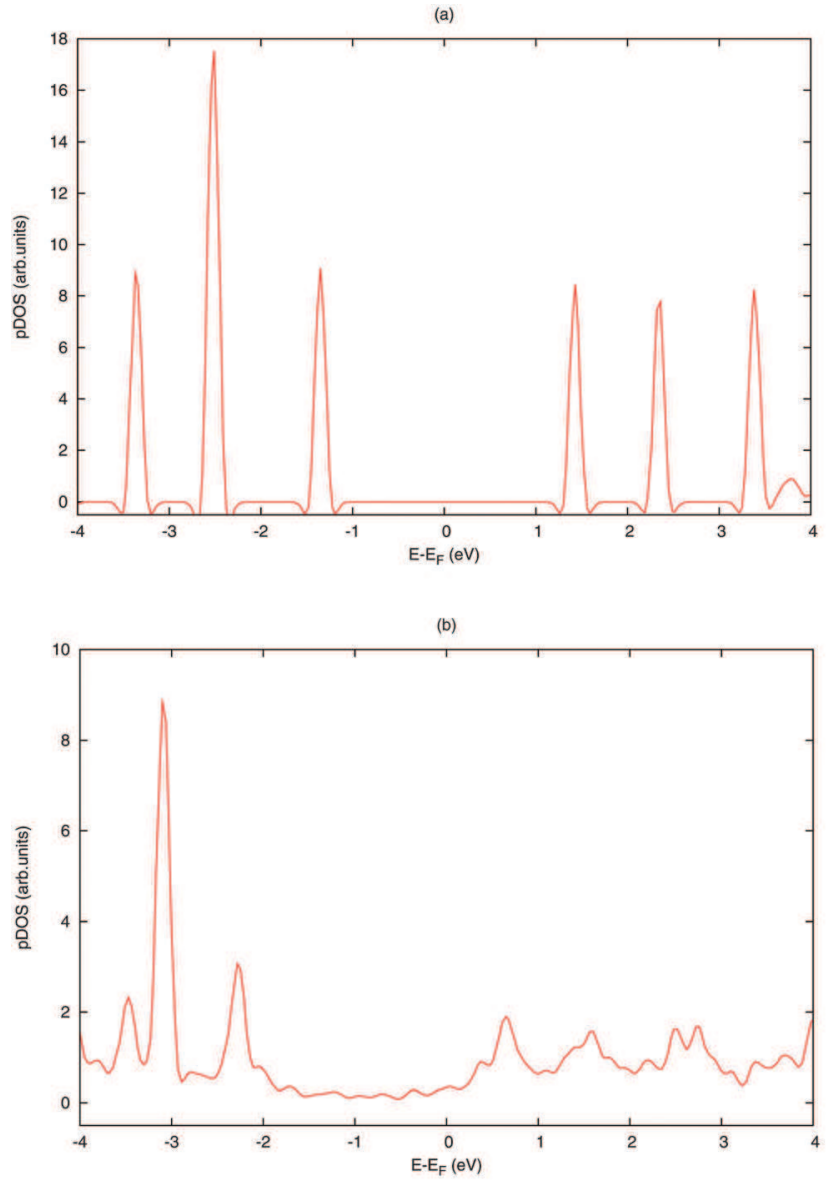

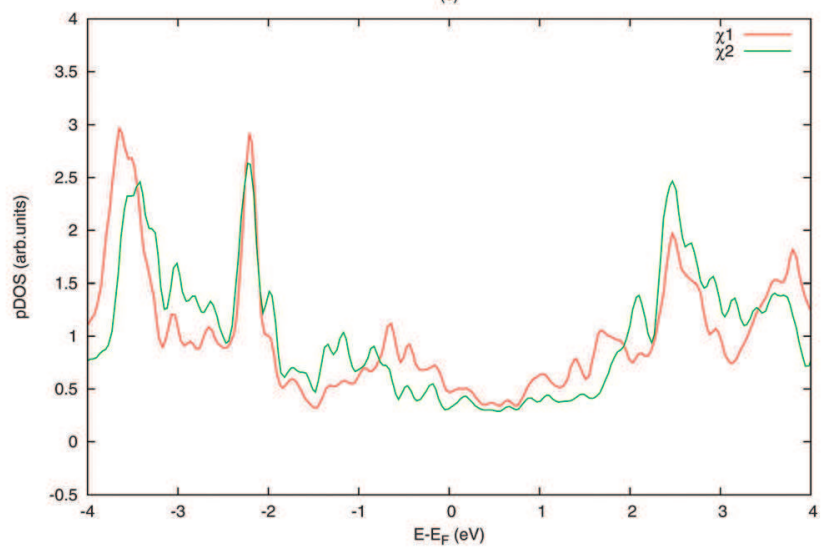

(d)

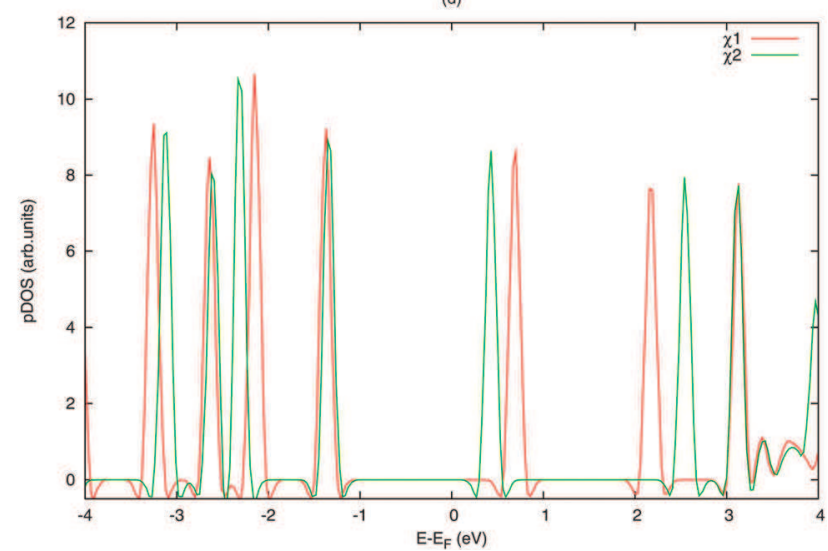

Fig. 8 Projected density of states (pDOS) onto the molecular orbitals before and after adsorption of the $\alpha$ 8-HQ molecule on the Al(111) surface. (a) Free $8-\mathrm{HQ}$ before adsorption; (b) $\varphi$ configuration; (c) $\chi 1$ and $\chi 2$ configurations; (d) separated 8-HQ and slab at the geometry after adsorption for $\chi 1$ and $\chi 2$ configurations.

but also on the reactivity of the metallic slab versus molecular species (the position of the $E_{\mathrm{F}}$ of the substrate to the HOMOLUMO gap of the molecule). For the hydrogenated species, the Fermi level of the metal was located just below the HOMO of the molecule and at $0.8 \mathrm{eV}$ of the LUMO. At first sight it could be concluded that the hydrogenated species would interact with the surface giving electrons to the metal. In fact, the calculation of the charge variation on the metal/molecule system showed as already said an electronic transfer from the metallic surface to the adsorbate.

The pDOS of the physisorbed $\alpha$ 8-HQ in Fig. 8(b) showed that the energy differences between the molecule orbitals were globally conserved (including the HOMO-LUMO gap). The position of these molecular levels were shifted significantly to lower energy by $1 \mathrm{eV}$. The other modification was a clear enlargement of molecular levels, especially for the unoccupied states. This indicated a small coupling between the adsorbate and the substrate. To further explore this low coupling we plotted the charge distribution variation with an isosurface value of $-0.0002 \mathrm{e}^{-3}$ (in Fig. 9) that was ten times smaller than the value of the isosurface in Fig. 4. It showed a tiny among of charge localized between the 8-HQ and the $\mathrm{Al}(111)$ surface that was not seen on the plot of $\Delta \rho$ with an isosurface of
-0.002 e $\AA^{-3}$ (in Fig. 4(a)). This picture is consistent with the small amount ( 0.2 electron) transferred from the substrate to the physisorbed 8-HQ molecule (in Table 3).

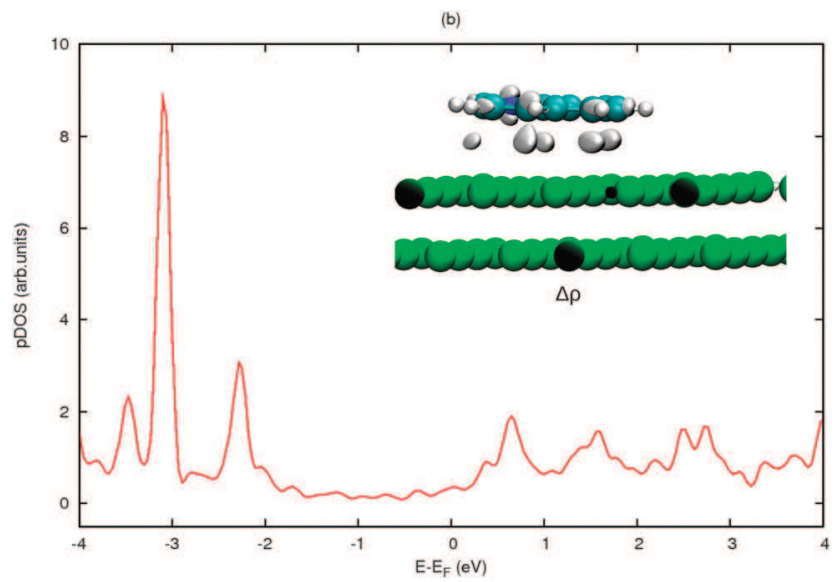

Fig. 9 Projected density of states (pDOS) onto the molecular orbitals after adsorption and charge distribution variation $\Delta \rho$ for the $\alpha 8-\mathrm{HQ}$ molecule physisorbed on the $\mathrm{Al}(111)$ surface $\varphi$ configuration (isosurface value: -0.0002 e $\AA^{-3}$ ). 
For the $\alpha$ 8-HQ molecule chemisorbed on the surface the pDOS are presented in Fig. 8(c). The pDOS onto the molecular orbitals were modified significantly during the adsorption process. These modifications were the consequence of the strong coupling between the substrate and the molecule. As expected molecular levels observed for the free $\alpha$ 8-HQ were no longer present in the final pDOS. New occupied molecular levels appeared between $-2 \mathrm{eV}$ and the Fermi level and were linked to the chemical bonding between the molecule and the aluminum surface atoms, with a change in the hybridization of the $\mathrm{N}$ and $\mathrm{C}_{2}\left(\chi_{1}\right)$ or $\mathrm{C}_{4}\left(\chi_{2}\right)$ atoms in the pyridine ring. From comparison of the pDOS for the $\chi_{1}$ and $\chi_{2}$ configurations, it could be concluded again that the $\chi^{2}$ configuration was the most stable one because of lower occupied bonding states than in the $\chi 1$ configuration, specially in the $-1.5 \mathrm{eV}$ to $0.5 \mathrm{eV}$ range. To gain insight in this bonding, we also plotted the pDOS for the $\chi 1$ and $\chi^{2}$ systems imposing a distance of $10 \AA$, between the substrate and the molecule, but freezing the geometry of the slab and of the $\alpha$ 8-HQ molecule at their optimized geometry when in interaction (Fig. 8(d)). This allowed to see the influence on the molecular orbitals energies of the deformation of the $\alpha$ 8-HQ molecule upon adsorption. It showed a significant shift of the unoccupied molecular orbitals levels of the deformed $\alpha$
8-HQ molecule to lower values and the gap was decreased by about $0.7 \mathrm{eV}$. The LUMO level was shifted toward the Fermi level of the metal and could favor the electron transfer from the metal to the adsorbate.

For $\tau 1$ and $\tau 2$ configurations of the tautomer, the pDOS in Fig. 10(b) were different than the pDOS of the $\chi 1$ and of $\chi^{2}$ configurations for the $\alpha 8$-HQ molecule. It is because the tautomer and the $\alpha$ 8-HQ molecule had different bonding characteristics to the Al surface. The difference in the bonding was visualized through the plot of charge density variation $\Delta \rho$. Comparing $\chi 1, \chi 2$ and $\tau 1, \tau 2$ configurations on Fig. 4 and 5, one can distinguish the supplementary charge localization just below the $\mathrm{O}$ atom, which confirmed the formation of strong $\mathrm{Al}-\mathrm{O}$ covalent bonds with short lengths of $1.82 \pm 0.01 \AA$ A. The new electronic states coming from the interaction of the molecular orbitals of the tautomer with the metal could not to be clearly identified on Fig. 10(b). But peaks on the pDOS in the range between $-2 \mathrm{eV}$ and $0 \mathrm{eV}$ were due to the molecule/surface coupling and they were clearly different in the $-2 \mathrm{eV}$ to $-1 \mathrm{eV}$ range when compared to that of the $\alpha$ 8-HQ chemisorbed configurations in the same range of energies. The states from $-2 \mathrm{eV}$ to $-1 \mathrm{eV}$ could thus be assigned to the bonding between the $\mathrm{O}$ atom and the $\mathrm{Al}$ surface in the tautomer/aluminum interaction.
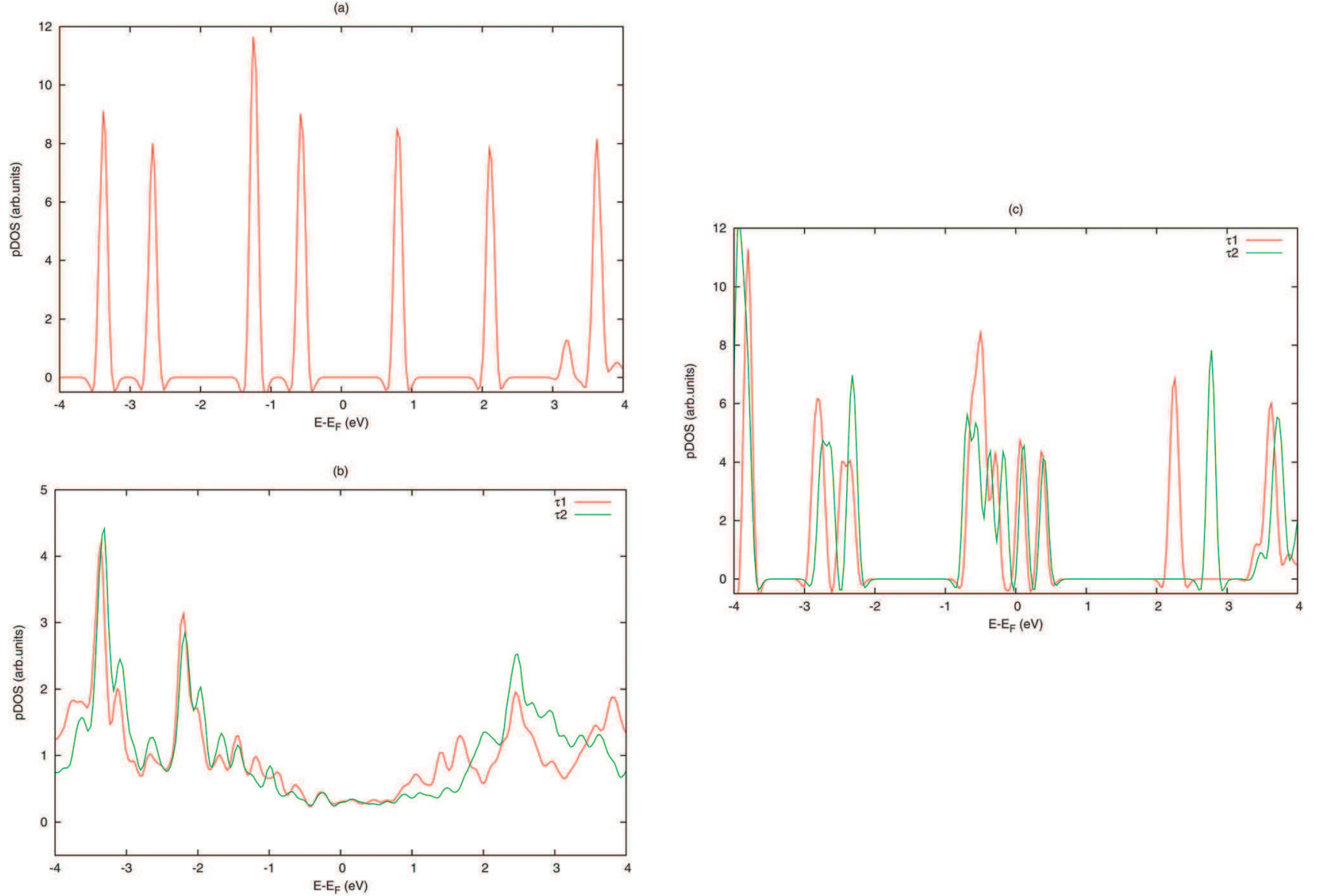

Fig. 10 Projected density of states (pDOS) onto the molecular orbitals before and after adsorption of the tautomer on the Al(111) surface. (a) Free tautomer before adsorption; (b) $\tau 1$ and $\tau 2$ configurations; (c) separated tautomer and slab at the geometry after adsorption for $\tau 1$ and $\tau 2$ configurations. 

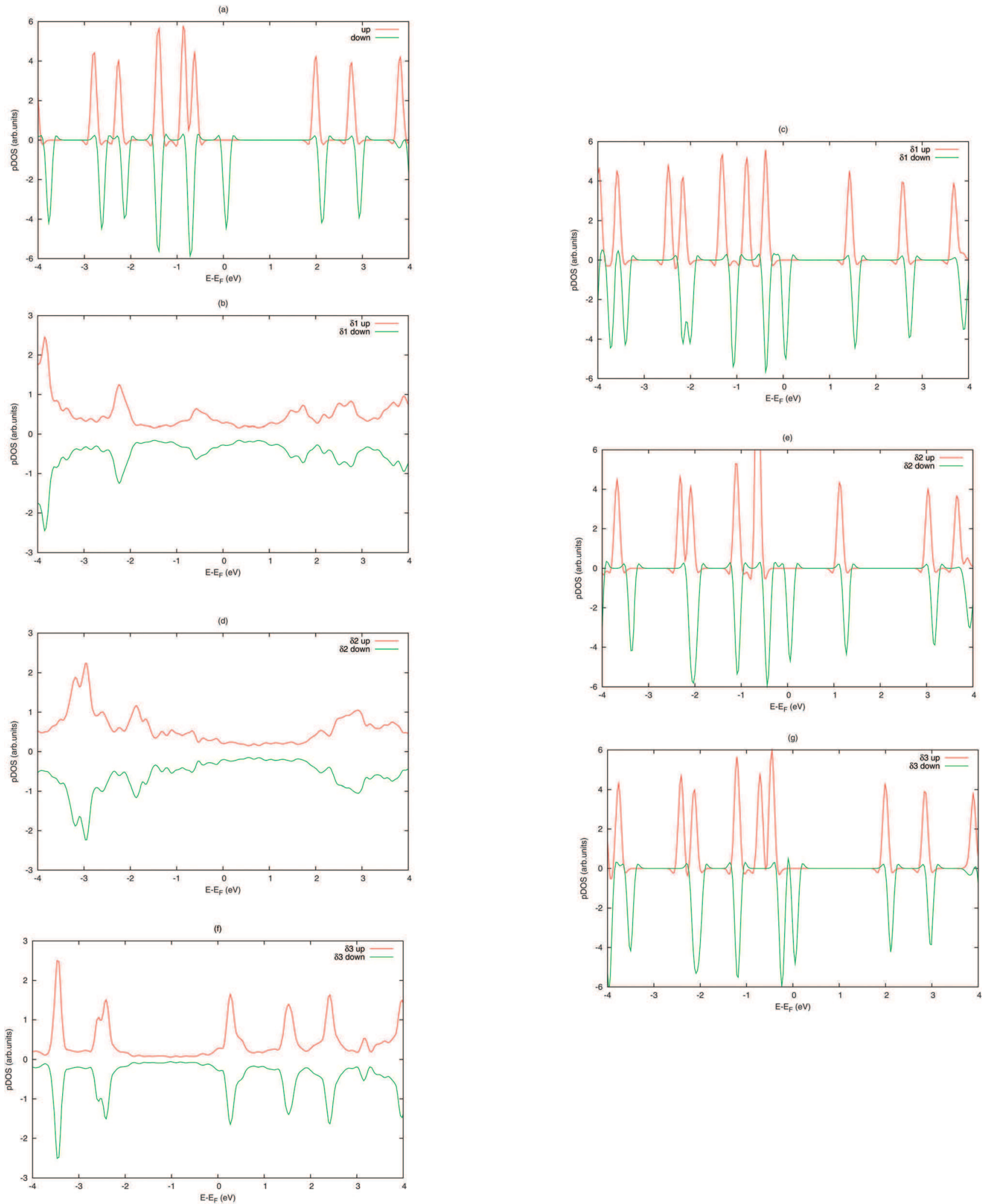

Fig. 11 Projected density of states (pDOS) up and down onto the molecular orbitals before and after adsorption of the dehydrogenated 8-HQ molecule on the Al(111) surface. (a) Free dehydrogenated before adsorption; (b), (d) and (f) $\delta 1, \delta 2$ and $\delta 3$ configurations respectively; (c), (e) and (g) separated molecule and slab after adsorption for $\delta 1, \delta 2$ and $\delta 3$ configurations respectively.

Such difference were also observed for new unoccupied states between $0 \mathrm{eV}$ and $+2 \mathrm{eV}$. Comparing the pDOS for the molecule and the substrate separated by the distance of $10 \AA$, in Fig. 10(a) (tautomer with optimized geometry in its free state) and in 

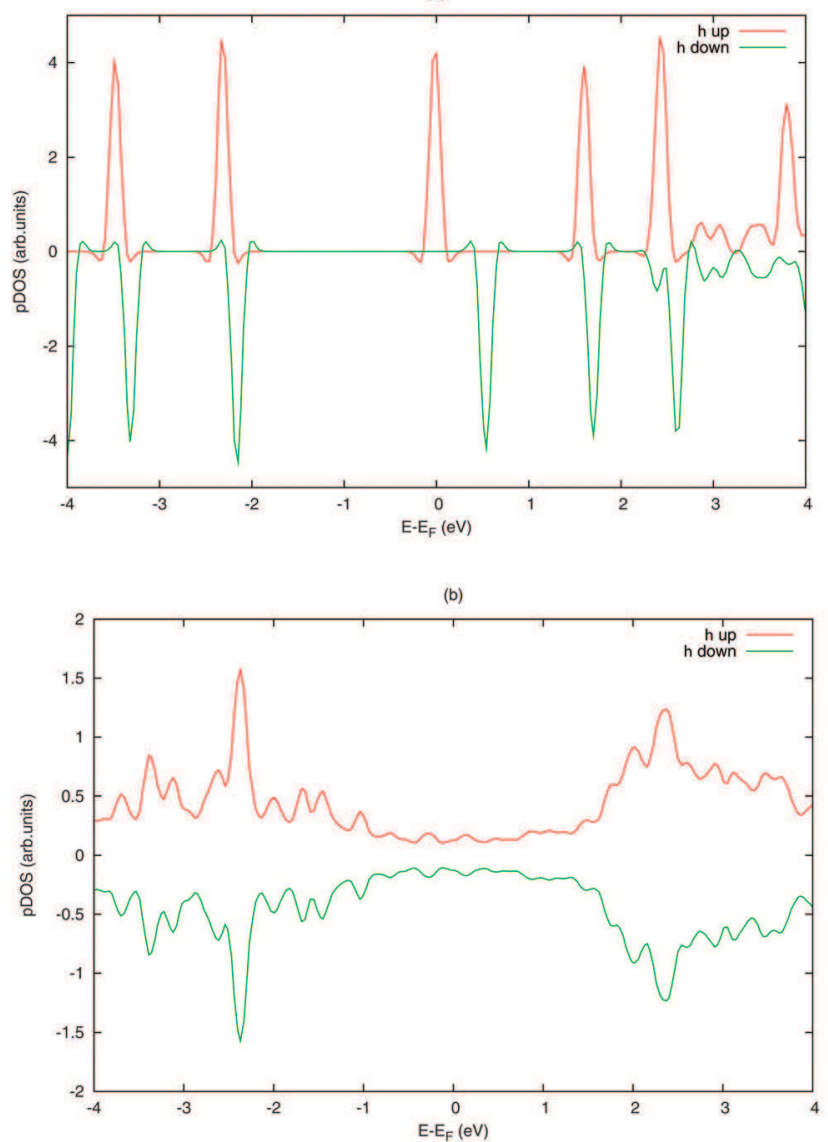

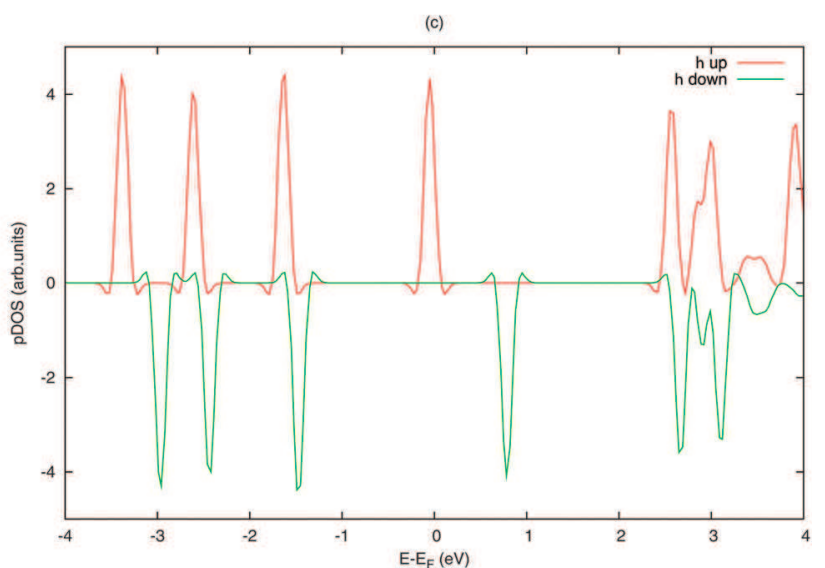

Fig. 12 Projected density of states (pDOS) up and down onto the molecular orbitals before and after adsorption of the hydrogenated 8-HQ molecule on the Al(111) surface. (a) Free hydrogenated before adsorption; (b) $\eta$ configuration; (c) separated molecule and slab after adsorption for $\eta$ configuration.

Fig. 10(c) (tautomer at its optimized geometry when adsorbed), we could again take into account the influence of the deformation of the molecule on the energy and the form of the projected density of the states. First, in Fig. 10(c) there were many occupied and unoccupied states near the Fermi level and no gap was observed. Thus for the tautomer, the molecular orbitals of the species after adsorption were more significantly modified than in the case of the $\alpha$ 8-HQ molecule, because of a stronger bonding with the $\mathrm{Al}(111)$ surface for the tautomer.

The pDOS onto the molecular orbitals for all configurations of the chimisorption of the dehydrogenated and hydrogenated 8-HQ molecule (Fig. 11(b), (d), (f) and 12(b)) were completely different from the pDOS for the free molecule (Fig. 11(a) and 12(a)). Upon adsorption the spin up and spin down pDOS became similar, there was no more unpaired molecular states. It could be explained by the electron transfer from the aluminum substrate to the molecule.

The shape of the pDOS for each $\delta$ and $\eta$ configurations were dissimilar from the pDOS for other ones. For the $\delta 1$ configuration, the first principal peak below $E_{\mathrm{F}}$ was located at $-0.6 \mathrm{eV}$, while the first principal massif of peaks above $E_{\mathrm{F}}$ was situated around $1.8 \mathrm{eV}$. The $\delta 2$ and $\eta$ configurations presented the same topology for the molecule chemisorbed on the $\mathrm{Al}(111)$ surface and there were many bonding states (due to molecule surface coupling) between $-2 \mathrm{eV}$ and $E_{\mathrm{F}}$ and above $+2 \mathrm{eV}$ on the pDOS. The slight difference in the pDOS between these two configurations was due to the presence or the absence of the Al-O bond and the weight of the Al-N bond, as showed in Fig. 6(b) and 7. In $\delta 3$ configuration, the contribution of the molecular orbitals appeared clearly for both occupied and unoccupied states. The occupied states showing a contribution from the molecular levels of the molecules were below $-2 \mathrm{eV}$ and were thus much lower than in the case of the $\delta 1$ and $\delta 2$ configurations. In this $\delta 3$ configuration, the molecule was bound to the $\mathrm{Al}$ surface bidentately by $\mathrm{N}$ and $\mathrm{O}$ atoms and there was no carbon atoms involved in the molecule/surface bonding. This kind of molecule/surface coupling did not require change in the hybridization of $\mathrm{C}_{2}$ or $\mathrm{C}_{4}$ atoms and thus the pDOS for separated molecule and slab after adsorption (Fig. 11(g)) were similar to that of the free molecule (Fig. 11(a)). Finally, the $\delta 3$ configuration presented a LUMO position very close to the Fermi level, suggesting that the system could easily accept more electrons.

\section{Conclusion}

The present work is a first step in the understanding of the aluminum corrosion inhibition mechanism. We investigated in details the interaction of the 8-hydroxyquinoline molecule and 
its derivatives with the $\mathrm{Al}(111)$ surface. The 8-HQ molecule has proven experimentally to be efficient against the corrosion of aluminum and its alloys. It is potentially present in aqueous solution as $\alpha$ 8-HQ, its tautomer, dehydrogenated and hydrogenated species. We performed intensive dispersion corrected DFT calculations and we limited our investigations to a low surface coverage. A physisorbed state was only found for the $\alpha$ 8-HQ molecule and taking into account the vdW corrections to the energy was necessary to get a negative adsorption energy and thus no metastable state. Among the $\alpha$ 8-HQ and its derivatives, the dehydrogenated 8-HQ molecule had the strongest coupling with the $\mathrm{Al}(111)$ surface.

For all the molecule studied, chemisorbed configurations imposed strong deformations of the adsorbate upon adsorption. We showed that the covalent metal/molecule bonding clearly involved strongly deformed configurations of the pyridine ring. Changes from $\mathrm{sp}^{2}$ to $\mathrm{sp}^{3}$ hybridization of carbon atoms were the main reason of the high deformation energies ( 0.55 to $2.27 \mathrm{eV}$ ). The carbon atoms involved in the bonding were in ortho or para positions of the $\mathrm{N}$ atom and they are known as the more electrophile sites on the pyridine ring. During the chemisorption process, electrons were thus transfered from the substrate to the atoms in these positions in molecules. The plot of the pDOS onto the molecule orbitals agreed with covalent bonding with creation of hybrid state upon adsorption.

\section{Acknowledgements}

This work was performed using HPC resources from CALMIP (Grant p12174) and from CINES (Grant c2013097076). It was supported by the National Research Agency (ANR support number ANR-2011 JS08 015 01).

\section{References}

1 N. Johansson, T. Osada, S. Stafström, W. R. Salaneck, V. Parente, D. A. dos Santos, X. Crispin and J. L. Bredas, J. Chem. Phys., 1999, 111, 2157.

2 E. R. de Sousa, E. P. Marques, E. N. Fernandes, J. Zhang and A. L. B. Marques, J. Braz. Chem. Soc., 2006, 17, 177-183.

3 M. E. Mahmoud, S. S. Haggag and T. M. Abdel-Fattah, Polyhedron, 2009, 28, 181-187.

4 M. D. Halls and H. B. Schlegel, Chem. Mater., 2001, 13, 2632-2640.

5 A. Rajagopal and A. Kahn, J. Appl. Phys., 1998, 84, 355.

6 Y. Q. Zhan, M. P. de Jong, F. H. Li, V. Dediu, M. Fahlman and W. R. Salaneck, Phys. Rev. B: Condens. Matter Mater. Phys., 2008, 78, 045208.

7 C. Barraud, P. Seneor, R. Mattana, S. Fusil, K. Bouzehouane, C. Deranlot, P. Graziosi, L. Hueso, I. Bergenti, V. Dediu, F. Petroff and A. Fert, Nat. Phys., 2010, 6, 615-620.

8 R. L. Twite and G. P. Bierwagen, Prog. Org. Coat., 1998, 33, 91-100.

9 M. L. Zheludkevich, K. A. Yasakau, S. K. Poznyak and M. G. S. Ferreira, Corros. Sci., 2005, 47, 3368-3383.
10 S. V. Lamaka, M. L. Zheludkevich, K. A. Yasakau, M. F. Montemor and M. G. S. Ferreira, Electrochim. Acta, 2007, 52, 7231-7247.

11 P. B. Raja and M. G. Sethuraman, Mater. Lett., 2008, 62, 113-116.

12 Y. Yin, T. Liu, S. Chen, T. Liu and S. Cheng, Appl. Surf. Sci., 2008, 255, 2978-2984.

13 X. Fu and X. He, Appl. Surf. Sci., 2008, 255, 1776-1781.

14 G. Boisier, A. Lamure, N. Pébere, N. Portail and M. Villatte, Surf. Coat. Technol., 2009, 203, 3420-3426.

15 G. Boisier, N. Portail and N. Pébère, Electrochim. Acta, 2010, 55, 6182-6189.

16 A. S. Fouda, A. A. Al-Sarawy, F. S. Ahmed and H. M. ElAbbasy, Corros. Sci., 2009, 51, 485-492.

17 G. Gece, Corros. Sci., 2008, 50, 2981-2992.

18 G. Gece, Corros. Sci., 2011, 53, 3873-3898.

19 T. G. Harvey, S. G. Hardin, A. E. Hughes, T. H. Muster, P. A. White, T. A. Markley, P. A. Corrigan, J. Mardel, S. J. Garcia, J. M. C. Mol and A. M. Glenn, Corros. Sci., 2011, 53, 2184-2190.

20 X. Li, S. Deng and X. Xie, Corros. Sci., 2014, 81, 162-175.

21 D. A. Winkler, M. Breedon, A. E. Hughes, F. R. Burden, A. S. Barnard, T. G. Harveyc and I. Cole, Green Chem., 2014, 16, 3349.

22 L. Garrigues, N. Pébère and F. Dabosi, Electrochim. Acta, 1996, 41, 1209-1215.

23 A. S. Yaro and H. A. Dahyool, Iraqi Journal of Chemical and Petroleum Engineering, 2009, 10, 19-25.

24 L. Song-mei, Z. Hong-rui and L. Jian-hua, Trans. Nonferrous Met. Soc. China, 2007, 17, 318-325.

25 I. Obot, D. Macdonald and Z. Gasem, Corros. Sci., 2015, DOI: 10.1016/j.corsci.2015.01.037.

26 S. K. Saha, A. Dutta, P. Ghosh, D. Sukulc and P. Banerjee, Phys. Chem. Chem. Phys., 2015, 17, 5679.

27 S. K. Saha, P. Ghosh, A. Hens, N. C. Murmu and P. Banerjee, Physica E, 2015, 66, 332.

28 A. Kokalj, S. Peljhan, M. Finšgar and I. Milošev, J. Am. Chem. Soc., 2010, 132, 16657-16668.

29 N. Kovačević and A. Kokalj, J. Phys. Chem. C, 2011, 115, 24189-24197.

30 N. Kovačević and A. Kokalj, Mater. Chem. Phys., 2012, 137, 331-339.

31 N. Kovačević and A. Kokalj, Corros. Sci., 2013, 73, 7-17.

32 S. Peljhan, J. Koller and A. Kokalj, J. Phys. Chem. C, 2014, 118, 933-943.

33 A. Kokalj, S. Peljhan and J. Koller, J. Phys. Chem. C, 2014, 118, 944-954.

34 A. Motta, M.-P. Gaigeot and D. Costa, J. Phys. Chem. C, 2012, 116, 12514-12524.

35 A. Motta, M.-P. Gaigeot and D. Costa, J. Phys. Chem. C, 2012, 116, 23418-23427.

36 T. Rebeiro, A. Motta, P. Marcus, M.-P. Gaigeot, X. Lopez and D. Costa, J. Inorg. Biochem., 2013, 128, 164-173.

37 Y. Xiao-Ci, Z. Hong, L. Ming-Dao, R. Hong-Xuan and Y. Lu-An, Corros. Sci., 2000, 42, 645-653.

38 S. D. Chakarova-Kack, O. Borck, E. Schröder and B. I. Lundqvist, Phys. Rev. B: Condens. Matter Mater. Phys., 2006, 74, 155402 . 
39 O. Borck and E. Schröder, J. Phys.: Condens. Matter, 2006, 18, 1-12.

40 O. Borck, P. Hyldgaard and E. Schröder, Phys. Rev. B: Condens. Matter Mater. Phys., 2007, 75, 035403.

41 C. Arrouvel, B. Diawara, D. Costa and P. Marcus, J. Phys. Chem. C, 2007, 111, 18164-18173.

42 S.-Q. Zhou, X.-H. Ju, F.-Q. Zhao and S.-Y. Xu, Appl. Surf. Sci., 2012, 258, 7334-7342.

43 K. Müller, A. P. Seitsonen, T. Brugger, J. Westover, T. Greber, T. Jung and A. Kara, J. Phys. Chem. C, 2012, 116, 23465-23471.

44 Y.-P. Wang, X.-F. Han, Y.-N. Wu and H.-P. Cheng, Phys. Rev. B: Condens. Matter Mater. Phys., 2012, 85, 144430.

45 S. Yanagisawa and Y. Morikawa, J. Phys.: Condens. Matter, 2009, 21, 064247.

46 S. Yanagisawa and Y. Morikawa, Chem. Phys. Lett., 2006, 420, 523-528.

47 S. Yanagisawa, K. Lee and Y. Morikawa, J. Chem. Phys., 2008, 128, 244704.

48 J. Zhang, P. Chen, B. Yuan, W. Ji, Z. Cheng and X. Qiu, Science, 2013, 342, 1242603.

49 G. Kresse and J. Hafner, Phys. Rev. B: Condens. Matter Mater. Phys., 1993, 47, 558.

50 G. Kresse and J. Furthmüller, Phys. Rev. B: Condens. Matter Mater. Phys., 1996, 54, 11169.

51 G. Kresse and J. Furthmüller, Comput. Mater. Sci., 1996, 6, 15-50.

52 P. E. Blöchl, Phys. Rev. B: Condens. Matter Mater. Phys., 1994, 50, 17953.

53 G. Kresse and D. Joubert, Phys. Rev. B: Condens. Matter Mater. Phys., 1999, 59, 1758.

54 J. P. Perdew, K. Burke and M. Ernzerhof, Phys. Rev. Lett., 1996, 77, 3865.
55 M. Methfessel and A. T. Paxton, Phys. Rev. B: Condens. Matter Mater. Phys., 1989, 40, 3616.

56 H. J. Monkhorst and J. D. Pack, Phys. Rev. B: Solid State, 1976, 13, 5188.

57 M. Dion, H. Rydberg, E. Schröder, D. C. Langreth and B. I. Lundqvist, Phys. Rev. Lett., 2004, 92, 246401.

58 S. Grimme, J. Comput. Chem., 2006, 27, 1787.

59 V. G. Ruiz, W. Liu, E. Zojer, M. Scheffler and A. Tkatchenko, Phys. Rev. Lett., 2012, 108, 146103.

60 V. G. R. Wei Liu, G.-X. Zhang, B. Santra, X. Ren, M. Scheffler and A. Tkatchenko, New J. Phys., 2013, 15, 053049.

61 W. Tang, E. Sanville and G. Henkelman, J. Phys.: Condens. Matter, 2009, 21, 084204.

62 P. Roychowdhury, Acta Crystallogr., Sect. B: Struct. Crystallogr. Cryst. Chem., 1978, 34, 1047-1048.

63 Q.-S. Li and W.-H. Fang, Chem. Phys. Lett., 2003, 367, 637-644.

64 A. E. Shchavlev, A. N. Pankratov and A. V. Shalabay, Int. J. Quantum Chem., 2006, 106, 876-886.

65 E. Bardez, I. Devol, B. Larrey and B. Valeur, J. Phys. Chem. B, 1997, 101, 7786-7793.

66 A. R. Katritzky and A. F. Pozharzki, Handbook of Heterocyclic Chemistry, Elsevier Science Ltd, 2nd edn, 2000.

67 M. C. Desjonqueres and D. Spanjaard, Concepts in surface Physics, Springer, 2nd edn, 1996.

68 J. B. Hudson, Surface science: An introduction, John Wiley, 1998.

69 C. J. Fall, N. Binggeli and A. Baldreschi, Phys. Rev. Lett., 2002, 88, 156802.

70 A. Michaelides, P. Hu, M.-H. Lee, A. Alavi and D. A. King, Phys. Rev. Lett., 2003, 90, 246103. 